\title{
Preclinical Safety of the Root Extract of Polygala tenuifolia Willdenow in Sprague-Dawley Rats and Beagle Dogs
}

\author{
Ki Young Shin, ${ }^{1,2}$ Beom Young Won, ${ }^{1}$ Hyun Jee Ha, ${ }^{1}$ Yeo Sang Yun, ${ }^{1}$ and Hyung Gun Lee \\ ${ }^{1}$ Research \& Development Center, Braintropia Co. Ltd., Anyang-si, Gyeonggi-do 431-716, Republic of Korea \\ ${ }^{2}$ Department of Microbiology, College of Natural Science, Dankook University, Cheonan-si, Chungnam 330-714, Republic of Korea \\ Correspondence should be addressed to Ki Young Shin; newsky73@braintropia.com
}

Received 30 July 2014; Revised 13 October 2014; Accepted 13 October 2014; Published 5 November 2014

Academic Editor: Khalid Rahman

Copyright (c) $2014 \mathrm{Ki}$ Young Shin et al. This is an open access article distributed under the Creative Commons Attribution License, which permits unrestricted use, distribution, and reproduction in any medium, provided the original work is properly cited.

\begin{abstract}
The root of Polygala tenuifolia Willdenow has been used for the treatment of insomnia, depression, and amnesia. However, the toxicological properties of the herb have been overlooked, because it has been used for a long time for various purposes. In this study, we evaluated the preclinical safety of the root extract in rats and beagle dogs. First, the acute oral toxicity was tested in both rats and dogs. In the rats, only one female of $2 \mathrm{~g} / \mathrm{kg}$ died, but no treatment-related death or clinical and gross findings were observed after the administration. No toxicological changes or mortalities related to the test substance were also observed after the administration in the dogs. Although vomiting, discoloration, or hemorrhage was found in some dogs, there were no serious abnormalities. Second, the subchronic toxicity was investigated in the rats. Two animals were found dead in the female group of $1,000 \mathrm{mg} / \mathrm{kg} / \mathrm{day}$, but there were no abnormal findings associated with the test substance. There also were no adverse effects on the clinical signs, body weight, and hematological and biochemical findings. Therefore, our results showed that the acute or subchronic toxicity of the root extract of Polygala tenuifolia might not be toxic to rats and dogs.
\end{abstract}

\section{Introduction}

Traditional oriental herbal prescriptions have regained popularity over the past decade. They are used widely for the treatment and prevention of various diseases $[1,2]$, because their long history of clinical application and natural origin seem to guarantee that the prescriptions will be effective and nontoxic [3]. Each plant used in such herbal prescriptions can provide opportunities for the development of herbal food products, dietary supplements, and functional foods [4]. However, the toxicological aspects of medicinal herbs or naturally occurring functional foods have been neglected due to their long history of use. It has been demonstrated that medicinal plants may have undesirable properties [5], because some individuals taking herbal medicines have reported certain side effects. Therefore, the use of any plant for medicinal purposes by no means guarantees the safety of such a plant. This fact raises concerns about the potential toxic effects resulting from short-term and long-term use of such medicinal plants. Data from acute and subchronic toxicity studies on medicinal plants or naturally occurring functional foods should be obtained to increase confidence in the safety of their use, particularly in the development of pharmaceuticals [6]. Polygala tenuifolia Willdenow is a perennial herbaceous plant distributed widely in China and Korea. In Asia, it is a well-known traditional medicine for the treatment of phlegm and detumescence. Traditional medicines are prepared from the roots of $P$. tenuifolia because of its expectorant, tonic, tranquilizing, and antipsychotic properties [7-9]. In particular, the herb is used against insomnia, neurasthenia, amnesia, depression, anxiety-related palpitations, restlessness, disorientation, dementia, and memory failure [10, 11]. Previously, we reported that the root extract of $P$. tenuifolia was shown to enhance memory and cognitive function in two animal models and two human models [12-15]. The extract has been shown to contain C-glycosides, triterpene saponins, sucrose esters, and oligosaccharide esters $[16,17]$. It also contains various substances, such as tenuigenin, tenuifolin, DISS $\left(3,6^{\prime}\right.$ disinapoyl sucrose), and TMCA (3,4,5-trimethoxycinnamic acid), which have been shown to have proliferative and protective effects on hippocampal neurons $[18,19]$. Several 
researchers have demonstrated the effects of $P$. tenuifolia, but information on its safety is lacking. Therefore, systematic evaluation of the safety of the root extract of this herb is necessary for the development of new foods or drugs. In this study, an alcohol extract from the dried root of $P$. tenuifolia was prepared, and its safety was evaluated using an acute oral toxicity test and a subchronic oral toxicity test in Sprague-Dawley rats and beagle dogs in accordance with two standards: the Korea Food and Drug Administration Notification numbers 2005-60 and 2005-79.

\section{Materials and Methods}

2.1. Preparation of the Root Extract of Polygala tenuifolia. The dried root extract of Polygala tenuifolia (500 g) was refluxed with $75 \%$ ethanol for $4 \mathrm{hr}$ in a boiling water bath. This procedure was repeated twice and the ethanol solution was concentrated under a vacuum. The resulting concentrated ethanol fraction (125 g) of the plant root was used for this study [12].

\subsection{Experimental Animals and Animal Husbandry. Six-} week-old specific pathogen-free Sprague-Dawley (HSD; SD) rats were used. Six animals of each sex for the acute oral toxicity study and 40 animals of each sex for the subchronic oral toxicity study were received from Koatech Co. (Pyeongtaeksi, Gyeonggi-do, Korea), Ltd. For the acute oral toxicity study, six beagle dogs of each sex at 6 months of age were obtained fromtheHanlim Laboratory Animals Company (Hwaseongsi, Gyeonggi-do, Korea). The animal room was maintained at a temperature of $23 \pm 3^{\circ} \mathrm{C}$, with a relative humidity of $55 \pm$ $15 \%$, air ventilation of $10-20$ times/h, and ambient light (150$300 \mathrm{Lux}$ ) controlled to produce a $12 \mathrm{~h}$ light/dark cycle. Animals were given irradiation-sterilized pellet feed and ground water disinfected by an ultraviolet sterilizer and ultrafiltered ad libitum. The dogs were reared in stainless steel cages $(8000$ $\times 900 \times 750 \mathrm{~mm}$ ), and identification cards showing their study number and animal number were attached to the cages.

2.3. Study Design Overview. This study was conducted in compliance with the Good Laboratory Practice (GLP) and Test Guidelines of the Organization for Economic Cooperation and Development $[20,21]$ and the Korea Food and Drug Administration $[22,23]$ at the GLP Institute approved by the KFDA (Korea Food and Drug Administration). The study protocol was approved by the Institutional Animal Care and Use Committee of the institute, which is accredited by the Association for Assessment and Accreditation of Laboratory Animal Care International, 2010.

2.3.1. Acute Oral Toxicity Study in Rats. After a 7-day quarantine and acclimatization period, ten healthy animals of each gender at 6 weeks of age were used. The study included two groups: a control group given no treatment and an experimental group given $2,000 \mathrm{mg} / \mathrm{kg}$, based on a preliminary study (data not shown). Each group consisted of five rats of each sex, and body weight ranges at dosing were 161.61$168.38 \mathrm{~g}$ for males and $144.98-158.17 \mathrm{~g}$ for females. The test substance was administered orally to each group. Thereafter, clinical signs and body weight were observed throughout the 15-day experimental period, and gross findings were observed on the scheduled necropsy day. This study was carried out in accordance with the standard operating procedures of SNUH-GLP (Non-Clinical Research Center, Biomedical Research Institute, Seoul National University Hospital).

2.3.2. Acute Oral Toxicity Study in Beagle Dogs. Six male and six female dogs were divided into three groups of four animals; then, two dogs of each gender were allocated. The study included three groups: a control group given no treatment and experimental groups exposed to $1,000 \mathrm{mg} / \mathrm{kg}$ and $2,000 \mathrm{mg} / \mathrm{kg}$. The body weight ranges at dosing were $7.269-$ $8.785 \mathrm{~kg}$ for males and $6.531-7.449 \mathrm{~kg}$ for females. The test substance was administered orally to each group. Thereafter, clinical signs, mortality, and body weight were observed throughout the 15-day experimental period, and gross findings were observed on the scheduled necropsy day. This study was carried out in accordance with the standard operating procedures of Preclinical Research Center, ChemOn (Yongin, Gyeonggi-do, Korea) Inc.

2.3.3. Subchronic Oral Toxicity Study in Rats. After a 7-day quarantine and acclimatization period, forty healthy animals of each gender at 6 weeks of age were used. A dose of $1,000 \mathrm{mg} / \mathrm{kg} /$ day was set as the high dose considering the results of a preliminary 1-week subchronic oral toxicity study (data not shown) and the characteristics of the test substance. Doses of 600 and $360 \mathrm{mg} / \mathrm{kg} /$ day were set as the middle and low doses, respectively, using a common ratio of 1.67 . The vehicle-treated group was administrated with sterile water for injection only. Each group consisted of 10 rats of each sex, and 10 rats of each sex and group were killed after a 90day treatment period. Body weight ranges at the beginning of dosing were 169.56-190.56 g for males and 125.30-142.00 g for females. The test substance was administered repeatedly by the oral route to each group for 90 days. The following items were examined during the experimental period: clinical signs, body weight, food and water consumption, ophthalmic examination, urinalysis, hematology, blood clotting time, serum biochemistry, necropsy findings, organ weight, and histopathology. This study was carried out in accordance with the standard operating procedures of Preclinical Research Center, ChemOn Inc.

\subsection{Observation and Examination Items of the Acute Oral Toxicity Study in Rats}

2.4.1. Clinical Signs. In the rat studies, clinical signs and mortality were observed continuously for the first $1 \mathrm{~h}$ after administration and every hour for $6 \mathrm{~h}$. Each animal was observed daily throughout the entire 15-day experimental period. Abnormal type and severity of signs, as well as the observation day and time, were recorded. The day of administration was set as day 1 .

2.4.2. Body Weight. Each rat was measured on days 1, 3, 7, and 14 using an electronic balance (Sartorius Co., Gottingen, Lower Saxony, Germany). 
2.4.3. Necropsy. On the scheduled necropsy day (day 15), all surviving animals were euthanized by exsanguination from the abdominal aorta and abdominal vena cava under a $\mathrm{CO}_{2}$ gas overdose and examined grossly for abnormalities of the body surface and internal organs.

\subsection{Observation and Examination Items of the Acute Oral Toxicity Study in Dogs}

2.5.1. Clinical Signs. In the dog studies, the clinical signs and mortalities were checked every hour for 6 hours after administration. Each animal was observed daily throughout the entire 15-day experimental period. Abnormal type and severity of signs, as well as the observation day and time, were recorded. The day of administration was set as day 1 .

2.5.2. Body Weight. All dogs were individually weighed before administration and on days 1, 3, 7, and 14 after the administration.

2.5.3. Necropsy. In the dog studies, the animals were anesthetized with ketamine (Yuhan Yanghaeng) and rompun (Bayer Korea) and euthanized by exsanguinations from the axillary artery and vein. All organs in the thoracic and abdominal cavities were observed grossly and the gross findings were recorded.

\subsection{Observation and Examination Items of the Subchronic Oral Toxicity Study in Rats}

2.6.1. Clinical Signs. All animals were observed daily for clinical signs and mortality. The type, date of occurrence, and the severity of the signs were recorded individually. The initial day of administration was set as day 1 .

2.6.2. Body Weight. Animals were weighed on the initial day of administration, once per week during the experimental period, and on the day of the necropsy. The body weight at the necropsy was measured after an overnight fast.

2.6.3. Food and Water Consumption. Food and water consumption were measured on the initial day of administration and then once per week during the experimental period. The amounts of food and water were measured before they were supplied to each cage, and the food and water remaining the next day were measured to calculate the difference, which was regarded as daily food and water consumption (g/rat/day).

2.6.4. Ophthalmic Examination. In the last week of observation, a mydriatic (Ocuhomapin, Lot number 013118, Samil Pharm Co., Korea) was dropped into both eyes of each animal to facilitate mydriasis after observing the external appearance of the eyes of five males and five females per group. The anterior parts of the eyes, the optic media, and the ocular fundus were then observed with an ophthalmoscope and a fundus camera (Genesis, Kowa Co., Tokyo, Japan). No abnormal signs were observed during the ophthalmic examination. Therefore, no eye photographs or further examinations were performed.
2.6.5. Urinalysis. Five males and five females per group were housed in metabolic cages for urine collection in the last week of observation, and fresh urine samples (about $1 \mathrm{~mL}$ ) were collected for $3 \mathrm{~h}$ and used for urinalysis and urine sediment tests. Additionally, the total urine volume was measured from urine samples collected for $24 \mathrm{~h}$. Test strips (Multistix 10 SG, Siemens, Washington, DC, USA) were dipped in about $0.3 \mathrm{~mL}$ of urine and the specific gravity, $\mathrm{pH}$, protein, glucose, ketone bodies, occult blood, bilirubin, urobilinogen, and nitrite levels were analyzed with an automatic analyzer (CliniTek 100, Siemens, Ames Division, Miles Laboratory, USA). Urine color was observed with the naked eye, and the result was input into the automatic analyzer. Approximately $0.7 \mathrm{~mL}$ of urine was centrifuged (Hanil MF300, Seoul, Korea) for $5 \mathrm{~min}$. The sediment was stained using the SternheimerMalbin method (Sternheimer and Malbin, 1951) and red blood cells (RBCs), white blood cells (WBCs), epithelial cells, and casts were observed under a microscope.

2.6.6. Hematology. Approximately $1 \mathrm{~mL}$ of the blood taken during the necropsy was placed into a CBC bottle (Vacutainer $3 \mathrm{~mL}$, Becton Dickinson, Franklin Lakes, NJ, USA) containing EDTA-2K anticoagulant. The following parameters were measured with a Coulter counter (ADVIA 2120, Siemens, Ames Division, Miles Laboratory, USA): white blood cell count, red blood cell count, hemoglobin, hematocrit, mean corpuscular volume, mean corpuscular hemoglobin, mean corpuscular hemoglobin concentration, red cell distribution width, hemoglobin distribution width, platelets, mean platelet volume, and WBC differential count (neutrophils, lymphocytes, monocytes, eosinophils, basophils, and large unstained cells). $1.8 \mathrm{~mL}$ of the blood taken during the necropsy was dispensed into a microtube containing $0.2 \mathrm{~mL}$ $3.2 \%$ sodium citrate, and plasma was obtained from centrifugation (Eppendorf, Hamburg, Germany) for $10 \mathrm{~min}$ to assess the blood clotting time. The prothrombin time and activated partial thromboplastin time were measured in seconds from plasma using the nephelometric analysis method (Woziwodzki, 1970) with a coagulation time analyzer (ACL 100, Instrumentation Laboratory, Bedford, MA, USA).

2.6.7. Serum Biochemistry. More than $2 \mathrm{~mL}$ of the blood taken during the necropsy was added to a $5 \mathrm{~mL}$ Vacutainer tube (IMPROBE, Germany) containing a clot activator. The blood was coagulated by maintaining it at room temperature for 15-20 min and was then centrifuged (3,000 rpm, 1,500 RCF, MF300, Hanil, Korea) for $10 \mathrm{~min}$. The following parameters were measured with a serum biochemistry analyzer (AU400, Olympus, Tokyo, Japan): aspartate aminotransferase, alanine aminotransferase, alkaline phosphatase, creatine phosphokinase, total bilirubin, glucose, total cholesterol, triglycerides, total protein, albumin, albumin/globulin ratio, blood urea nitrogen, creatinine, inorganic phosphorus, and calcium ions. The electrolytes were measured with the electrolyte autoanalyzer (644 Na, K, Cl Analyzer, Ciba-Corning, USA).

2.6.8. Necropsy and Organ Weight. Before the scheduled necropsy, all surviving animals were fasted overnight (for 
16-20 h) and euthanized with isoflurane (Ifran liquid, Hana Pharm. Co., Korea) inhalation on the day of the necropsy. After anesthesia was confirmed, blood was taken from the posterior vena cava for hematology and serum biochemistry analyses. The abdominal aorta and posterior vena cava were cut to euthanize the animals. All organs of the body surface, subcutis, head, and all internal organs of the abdominal and thoracic cavities were observed grossly. Next, the pituitary gland, ovaries, uterus, adrenal glands, thymus, prostate gland, testes, epididymides, spleen, kidneys, heart, lung, brain, and liver were removed and weighed with an electronic balance (BP221S, Sartorius Co., Gottingen, Lower Saxony, Germany), and all paired organs were measured separately. The absolute organ weights were converted to relative organ weights based on the organ-to-fasted body weight ratios.

2.6.9. Histopathology. Microscopic examinations were performed on the preserved organs and tissues taken from all animals in the vehicle-treated and high dose-treated groups. All gross lesions as defined by the study pathologist were also included in the examination. The eyes and the optic nerves were preserved in Davidson's fixative, and the testes and epididymides were preserved in Bouin's fixative. The following organs and tissues were fixed in $10 \%$ neutral buffered formalin solution: the thymus, spleen, pancreas, stomach, duodenum, jejunum, ileum, cecum, colon, rectum, mesenteric lymph nodes, mandibular lymph nodes, salivary gland, thyroid gland (including parathyroid gland), Harderian gland, heart, lung, kidneys, adrenal glands, liver, aorta, brain, pituitary gland, tongue, trachea, esophagus, sternum, thoracic spinal cord, femorotibial joint, peripheral nerve (sciatic), skeletal muscle (femoral), prostate gland, seminal vesicles, ovaries, uterus, vagina, urinary bladder, and skin (including mammary gland).

2.7. Statistical Analysis. In the rat studies, data are presented as mean \pm standard deviation. Body weight, food and water consumption, total volume of urine, hematology and serum biochemistry, and absolute and relative organ weights were assumed to be normally distributed and were analyzed by a one-way analysis of variance (ANOVA) [24]. The assumption of homogeneity was tested using Levene's test [25]. If the overall ANOVA was significant and the assumption of homogeneity of variance was met, Duncan's multiple-range test was used as a post hoc test to identify significantly different groups from the vehicle control group [26]. Scheffe's test was used if the sample size was unequal between the groups [27]. If the assumption of homogeneity of variance was not met, Dunnett's T3 test was used as the post hoc test [28]. Student's $t$-test was used to analyze the differences in means between the two independent groups. The urinalysis data were ranktransformed and analyzed by the nonparametric KruskalWallis $H$-test [29]. If a statistically significant difference was observed between groups, the Mann-Whitney $U$ test was used to identify the groups that were significantly different from the vehicle control group [30]. SPSS $10.1 \mathrm{~K}$ was used for all statistical analyses (Chicago, IL, USA). A $P<0.05$ was considered significant.
In the dog studies, data are presented as mean \pm standard deviation. Body weight, food and water consumption, total volume of urine, hematology and serum biochemistry, and absolute and relative organ weights were assumed to be normally distributed and were analyzed by a one-way analysis of variance (ANOVA) [24]. SPSS $10.1 \mathrm{~K}$ was used for all statistical analyses (Chicago, IL, USA). A $P<0.05$ was considered significant.

\section{Results}

3.1. Acute Oral Toxicity Study in Rats. The test substance was orally administered to a single group of five male and five female SD rats at 7 weeks of age in dosage levels of $2 \mathrm{~g} / \mathrm{mL} / \mathrm{kg}$ B.W. Only one female rat given $2 \mathrm{~g} / \mathrm{mL} / \mathrm{kg}$ displayed piloerection and activity decrease 1 day after the treatment and died within the same day. However, the gross necropsy results showed no treatment-related changes and revealed no evidence of specific toxicity related to the test substance. Also, there was a statistically significant decrease in the body weights at 1 day in all test group rats (Table 1). However, the body weights of the test groups recovered. Therefore, this was a temporary side effect from the test substance. But, all rats except the aforementioned female rat were not noted in the mortality, clinical, and gross findings.

\subsection{Acute Oral Toxicity in Beagle Dogs}

3.2.1. Clinical Signs and Mortality. No dogs died during the experimental period. After the administration of the test substance, vomiting was observed. In the male group given $1,000 \mathrm{mg} / \mathrm{kg}$ (Table 2 ), very slight vomiting of the test substance at $3 \mathrm{hr}$ and vomiting of the food at $5 \mathrm{hr}$ were observed in one male. In addition, in the male group given $2,000 \mathrm{mg} / \mathrm{kg}$, severe vomiting was observed in two males at $30 \mathrm{~min}$, and further vomiting of the food was observed in a male on day 5. As shown in Table 3, vomiting of the food was observed in one vehicle-treated female on day 1 , moderate vomiting of the test substance was observed in one female given $1,000 \mathrm{mg} / \mathrm{kg}$ at $1 \mathrm{hr}$, and severe vomiting of the test substance was observed in two females given $2,000 \mathrm{mg} / \mathrm{kg}$ at $30 \mathrm{~min}$. Vomiting of the food was observed in all female groups on day 7 .

3.2.2. Body Weights. The body weight was observed throughout the 15-day experimental period (Table 4). In the males, a loss of body weight was observed in a male given $1,000 \mathrm{mg} / \mathrm{kg}$ on days 1 and 7 and in a male given $2,000 \mathrm{mg} / \mathrm{kg}$ on day 3 . In the females, a loss of the body weight was observed in a vehicle-treated female on day 3 , in a female given $1,000 \mathrm{mg} / \mathrm{kg}$ on days 1 and 7 , and in a female given $2,000 \mathrm{mg} / \mathrm{kg}$ on days 1 and 7.

3.2.3. Necropsy. As shown in Table 5, hemorrhage of the mucosa of the duodenum and dark red discoloration in the right lobule of a lung were observed in one male. However, no abnormalities were observed in other males and females. 
TABLE 1: Body weight values of Sprague-Dawley rats orally treated with Polygala tenuifolia extracts in acute oral toxicity study.

\begin{tabular}{|c|c|c|c|c|}
\hline \multicolumn{5}{|c|}{ Group summary of body weight } \\
\hline \multirow{2}{*}{ Dosage in days } & \multicolumn{2}{|c|}{ (Vehicle-treated group, $0 \mathrm{~g} / 10 \mathrm{~mL} / \mathrm{kg} / \mathrm{B} . \mathrm{W}$. ) } & \multicolumn{2}{|c|}{ (Test substance-treated group, $2 \mathrm{~g} / 10 \mathrm{~mL} / \mathrm{kg} / \mathrm{B} . \mathrm{W}$.) } \\
\hline & Mean \pm S.D. & $N$ & Mean \pm S.D. & $N$ \\
\hline \multicolumn{5}{|l|}{ Male } \\
\hline-1 & $212.70 \pm 2.955$ & 5 & $240.20 \pm 2.953$ & 5 \\
\hline 0 & $193.53 \pm 2.767$ & 5 & $191.71 \pm 3.125$ & 5 \\
\hline 1 & $218.14 \pm 1.530$ & 5 & $192.55^{*} \pm 13.589$ & 5 \\
\hline 7 & $277.23 \pm 8.416$ & 5 & $255.49^{*} \pm 15.501$ & 5 \\
\hline 14 & $328.20 \pm 19.827$ & 5 & $313.22 \pm 13.880$ & 5 \\
\hline \multicolumn{5}{|l|}{ Female } \\
\hline-1 & $197.17 \pm 4.587$ & 5 & $197.16 \pm 4.621$ & 5 \\
\hline 0 & $163.89 \pm 5.228$ & 5 & $159.58 \pm 4.439$ & 5 \\
\hline 1 & $181.93 \pm 8.6178$ & 5 & $163.81^{*} \pm 10.634$ & 4 \\
\hline 7 & $215.62 \pm 14.040$ & 5 & $203.59 \pm 11.938$ & 4 \\
\hline 14 & $235.38 \pm 21.433$ & 5 & $231.21 \pm 6.933$ & 4 \\
\hline
\end{tabular}

S.D.: Standard deviation.

$N$ : Number of animals.

${ }^{*} P<0.05$ compared to the vehicle-treated group.

(Unit: g).

\subsection{Subchronic Oral Toxicity Study in Rats}

3.3.1. Clinical Signs and Mortality. A rat was found dead on day 50 and another on day 67 after administration in the female group with $1,000 \mathrm{mg} / \mathrm{kg} /$ day. In both dead rats, abnormal fur, dirty noses, and hypothermia were observed on the day before death. There were no abnormal findings that were associated with the administration of the test substance other than minor observed signs such as scratched wounds, crust formation, scarring, and the loss of teeth, which occurred at a low frequency with no dose-relationship during the study period (data not shown).

3.3.2. Body Weight and Food and Water Consumption. As a result of the observations of body weight changes and body weight gains for 13 weeks during the administration and observation periods, there were no statistically significant changes in all treatment groups of both sexes compared to the vehicle-treated group. The food consumption in the male group of $360 \mathrm{mg} / \mathrm{kg} /$ day was significantly increased at weeks 4 and 10 after the administration compared to the vehicletreated group (Tables 6 and 7$)(P<0.05$ or $P<0.01)$. There was no significant change in water consumption in all groups of both sexes compared to the vehicle-treated group.

3.3.3. Ophthalmic Examination. In all groups, there were no particular signs observed from external eye examinations at grouping and ophthalmic examinations using a fundus camera in the final week of administration (data not shown).

3.3.4. Urinalysis. There were no particular signs associated with the administration of the test substance as a result of urinalysis performed in the final administration week (data not shown).
3.3.5. Hematology. The RDW (red cell distribution width) in the male group administered with $1,000 \mathrm{mg} / \mathrm{kg} /$ day significantly decreased compared to the vehicle-treated group (Tables 8 and 9) $(P<0.01)$, but no consistent changes were observed in the male or female groups in association with the administration of the test substance in other examination items. There were no significant changes between the groups as a result of measurement of PT (prothrombin time) and APTT (activated partial thromboplastin time) (data not shown).

3.3.6. Serum Biochemistry. As a result of serum biochemical examinations using the serum of collected blood during the necropsy (Tables 10 and 11), dose-related decreasing tendencies of ALT, BUN, GLU, AST, ALP, CHO, PRO, and $\mathrm{CPK}$ and dose-related increases of $\mathrm{A} / \mathrm{G}, \mathrm{Na}^{+}$, and $\mathrm{Cl}^{-}$were observed in the males. In addition, statistically significant dose-dependent decreases of ALT, BUN, and GLU were observed compared to the vehicle-treated group $(P<0.05$ or $P<0.01)$ and significant dose-dependent increases of A/G, $\mathrm{Na}^{+}$, and $\mathrm{Cl}^{-}$were observed compared to the vehicletreated group $(P<0.01)$. In the female groups, no statically significant changes were observed in all measurement items.

3.3.7. Necropsy. As a result of the scheduled necropsy of live animals at 13 weeks after the administration, no notable doserelated changes were observed in either males or females. For males, enlargement of the spleen was observed in one case in the vehicle-treated group and one case in the $600 \mathrm{me} / \mathrm{kg} / \mathrm{day}$ treated group, a solid brown nodule of the prostate gland was observed in one case in the vehicle-treated group, and diffuse red spots or a flare-up of the thymus was observed in one case in the vehicle-treated group and one case in the test substance-treated groups. For the females, the retention 
TABLE 2: Incidence of clinical signs of male beagle dogs orally treated with Polygala tenuifolia extracts in single dose oral toxicity study.

\begin{tabular}{|c|c|c|c|c|}
\hline \multicolumn{5}{|c|}{ Sex: male } \\
\hline \multirow{2}{*}{ Day } & \multirow{2}{*}{ Signs observed } & \multicolumn{3}{|c|}{ Group } \\
\hline & & 0 & 1,000 & 2,000 \\
\hline \multirow{2}{*}{$0-1$ (0.5 hours) } & Appears normal & $2 / 2^{*}$ & $2 / 2$ & $0 / 2$ \\
\hline & Vomiting (severe) & $0 / 2$ & $0 / 2$ & $2 / 2$ \\
\hline 0-2 (1 hour) & Appears normal & $2 / 2$ & $2 / 2$ & $2 / 2$ \\
\hline $0-3$ (2 hours) & Appears normal & $2 / 2$ & $2 / 2$ & $2 / 2$ \\
\hline \multirow{2}{*}{$0-4$ (3 hours) } & Appears normal & $2 / 2$ & $1 / 2$ & $2 / 2$ \\
\hline & Vomiting (mild) & $0 / 2$ & $1 / 2$ & $0 / 2$ \\
\hline $0-5$ (4 hour) & Appears normal & $2 / 2$ & $2 / 2$ & $2 / 2$ \\
\hline \multirow{2}{*}{$0-6$ (5 hours) } & Appears normal & $2 / 2$ & $1 / 2$ & $2 / 2$ \\
\hline & Vomiting (food) & $0 / 2$ & $1 / 2$ & $0 / 2$ \\
\hline $0-7$ (6 hours) & Appears normal & $2 / 2$ & $2 / 2$ & $2 / 2$ \\
\hline 1 & Appears normal & $2 / 2$ & $2 / 2$ & $2 / 2$ \\
\hline 2 & Appears normal & $2 / 2$ & $2 / 2$ & $2 / 2$ \\
\hline 3 & Appears normal & $2 / 2$ & $2 / 2$ & $2 / 2$ \\
\hline 4 & Appears normal & $2 / 2$ & $2 / 2$ & $2 / 2$ \\
\hline \multirow{2}{*}{5} & Appears normal & $2 / 2$ & $2 / 2$ & $1 / 2$ \\
\hline & Vomiting (food) & $0 / 2$ & $0 / 2$ & $1 / 2$ \\
\hline 6 & Appears normal & $2 / 2$ & $2 / 2$ & $2 / 2$ \\
\hline 7 & Appears normal & $2 / 2$ & $2 / 2$ & $2 / 2$ \\
\hline 8 & Appears normal & $2 / 2$ & $2 / 2$ & $2 / 2$ \\
\hline 9 & Appears normal & $2 / 2$ & $2 / 2$ & $2 / 2$ \\
\hline 10 & Appears normal & $2 / 2$ & $2 / 2$ & $2 / 2$ \\
\hline 11 & Appears normal & $2 / 2$ & $2 / 2$ & $2 / 2$ \\
\hline 12 & Appears normal & $2 / 2$ & $2 / 2$ & $2 / 2$ \\
\hline 13 & Appears normal & $2 / 2$ & $2 / 2$ & $2 / 2$ \\
\hline 14 & Appears normal & $2 / 2$ & $2 / 2$ & $2 / 2$ \\
\hline
\end{tabular}

${ }^{*}$ Number of animals with the sign/number of animals examined.

of a clear fluid in the uterus was observed in the vehicletreated group and the 360,600 , and $1,000 \mathrm{mg} / \mathrm{kg} /$ day-treated groups (2, 4, 3, and 2 cases, resp.) and diffuse red spots in the thymus and dark yellowish brown discoloration of the lung were observed in the $600 \mathrm{mg} / \mathrm{kg} /$ day-treated group in two cases and one case, respectively. Additionally, enlargement of the submandibular lymph node was observed in one case in the $1,000 \mathrm{mg} / \mathrm{kg} /$ day-treated group. As a result of the necropsy of two dead females of the $1,000 \mathrm{mg} / \mathrm{kg} /$ day-treated group, diffuse red spots or dark red coloration in the lung and diffuse red spots in the anterior stomach and in the thymus were observed along with gas retention due to postmortal changes (data not shown).

3.3.8. Organ Weight. For males, the absolute and relative weights of the thymus showed significant increases in the 360 and $600 \mathrm{mg} / \mathrm{kg} /$ day-treated groups compared to the vehicletreated group (Tables 12 and 13) $(P<0.05$ or $P<0.01)$ and the relative weight of the left epididymis showed a significant decrease in the $600 \mathrm{mg} / \mathrm{kg} /$ day-treated group compared to the vehicle-treated group $(P<0.05)$, but these changes were not dose-related. For females, the relative weight of the liver
TABLE 3: Incidence of clinical signs of female beagle dogs orally treated with Polygala tenuifolia extracts in single dose oral toxicity study.

\begin{tabular}{|c|c|c|c|c|}
\hline \multicolumn{5}{|c|}{ Sex: female } \\
\hline \multirow{2}{*}{ Day } & \multirow{2}{*}{ Signs observed } & \multicolumn{3}{|c|}{ Group } \\
\hline & & 0 & 1,000 & 2,000 \\
\hline \multirow{2}{*}{$0-1$ (0.5 hours) } & Appears normal & $2 / 2^{*}$ & $2 / 2$ & $0 / 2$ \\
\hline & Vomiting (severe) & $0 / 2$ & $0 / 2$ & $2 / 2$ \\
\hline \multirow{2}{*}{$0-2$ (1 hour) } & Appears normal & $2 / 2$ & $1 / 2$ & $2 / 2$ \\
\hline & Vomiting (moderate) & $0 / 2$ & $1 / 2$ & $0 / 2$ \\
\hline $0-3$ (2 hours) & Appears normal & $2 / 2$ & $2 / 2$ & $2 / 2$ \\
\hline $0-4$ (3 hours) & Appears normal & $2 / 2$ & $2 / 2$ & $2 / 2$ \\
\hline $0-5$ (4 hours) & Appears normal & $2 / 2$ & $2 / 2$ & $2 / 2$ \\
\hline $0-6$ (5 hours) & Appears normal & $2 / 2$ & $2 / 2$ & $2 / 2$ \\
\hline $0-7$ (6 hours) & Appears normal & $2 / 2$ & $2 / 2$ & $2 / 2$ \\
\hline \multirow{2}{*}{1} & Appears normal & $1 / 2$ & $2 / 2$ & $0 / 2$ \\
\hline & Vomiting (food) & $1 / 2$ & $0 / 2$ & $0 / 2$ \\
\hline 2 & Appears normal & $2 / 2$ & $2 / 2$ & $2 / 2$ \\
\hline 3 & Appears normal & $2 / 2$ & $2 / 2$ & $2 / 2$ \\
\hline 4 & Appears normal & $2 / 2$ & $2 / 2$ & $2 / 2$ \\
\hline 5 & Appears normal & $2 / 2$ & $2 / 2$ & $2 / 2$ \\
\hline 6 & Appears normal & $2 / 2$ & $2 / 2$ & $2 / 2$ \\
\hline 7 & Vomiting (food) & $2 / 2$ & $2 / 2$ & $2 / 2$ \\
\hline 8 & Appears normal & $2 / 2$ & $2 / 2$ & $2 / 2$ \\
\hline 9 & Appears normal & $2 / 2$ & $2 / 2$ & $2 / 2$ \\
\hline 10 & Appears normal & $2 / 2$ & $2 / 2$ & $2 / 2$ \\
\hline 11 & Appears normal & $2 / 2$ & $2 / 2$ & $2 / 2$ \\
\hline 12 & Appears normal & $2 / 2$ & $2 / 2$ & $2 / 2$ \\
\hline 13 & Appears normal & $2 / 2$ & $2 / 2$ & $2 / 2$ \\
\hline 14 & Appears normal & $2 / 2$ & $2 / 2$ & $2 / 2$ \\
\hline
\end{tabular}

showed a significant increase in the $1,000 \mathrm{mg} / \mathrm{kg} /$ day-treated group compared to the vehicle-treated group $(P<0.05)$.

3.3.9. Histopathology. As a result of histopathological examination of rats with a scheduled necropsy, in the males in the vehicle-treated group, severe granulomatous inflammation of the prostate gland, moderate pyelonephritis in the kidney, sight cysts in the pituitary gland, and moderate granuloma in the liver were observed in one case, along with moderate inflammatory cell infiltration in the Hadrian gland and slight inflammatory cell infiltration in the heart (one case each). For the females, two cases of slight tubular regeneration in the kidney were observed in one case each. In the males with a scheduled necropsy from the $1,000 \mathrm{mg} / \mathrm{kg} /$ day-treated group, slight tubular remnants in the pituitary gland, slight granuloma in the liver, and a slight dilation of the lumen in the uterus were observed in one case in each group. In the low- and medium-dose groups, pale yellowish brown discoloration of the left lobe of the lungs (identified as focal alveolitis) was observed in one female from the $600 \mathrm{mg} / \mathrm{kg} / \mathrm{day}-$ treated group, and diffuse red spots in the thymus were observed in two cases (identified as focal hemorrhages). No abnormal findings were observed in the abnormal organs. 
TABle 4: Body weight values of beagle dogs orally treated with Polygala tenuifolia extracts in single dose oral toxicity study.

\begin{tabular}{|c|c|c|c|c|c|c|c|}
\hline \multicolumn{8}{|c|}{ Sex: male } \\
\hline \multirow{2}{*}{$\begin{array}{l}\text { Group } \\
(\mathrm{mg} / \mathrm{kg})\end{array}$} & \multicolumn{7}{|c|}{ Body weights (kg) } \\
\hline & Animal ID & $0 \mathrm{~d}$ & $1 \mathrm{~d}$ & $3 \mathrm{~d}$ & $7 \mathrm{~d}$ & $14 \mathrm{~d}$ & Gain \\
\hline \multirow{3}{*}{$\begin{array}{l}0 \\
(n=2)\end{array}$} & 1 & 7.283 & 7.350 & 7.694 & 7.741 & 8.226 & 0.943 \\
\hline & 2 & 8.075 & 8.043 & 8.097 & 8.185 & 8.448 & 0.373 \\
\hline & Mean & $7.679 \pm 0.560$ & $7.697 \pm 0.490$ & $7.896 \pm 0.285$ & $7.963 \pm 0.314$ & $8.337 \pm 0.157$ & $0.658 \pm 0.403$ \\
\hline \multirow{3}{*}{$\begin{array}{l}1,000 \\
(n=2)\end{array}$} & 3 & 8.785 & 8.549 & 8.666 & 8.551 & 8.938 & 0.153 \\
\hline & 4 & 7.961 & 7.863 & 8.128 & 8.068 & 8.352 & 0.391 \\
\hline & Mean & $8.373 \pm 0.583$ & $8.206 \pm 0.485$ & $8.397 \pm 0.380$ & $8.310 \pm 0.342$ & $8.645 \pm 0.414$ & $0.272 \pm 0.168$ \\
\hline \multirow{3}{*}{$\begin{array}{l}2,000 \\
(n=2)\end{array}$} & 5 & 8.282 & 8.225 & 8.437 & 8.511 & 8.918 & 0.636 \\
\hline & 6 & 7.269 & 7.595 & 7.375 & 7.588 & 7.959 & 0.690 \\
\hline & Mean & $7.776 \pm 0.716$ & $7.910 \pm 0.445$ & $7.906 \pm 0.751$ & $8.050 \pm 0.653$ & $8.439 \pm 0.678$ & $0.663 \pm 0.038$ \\
\hline \multicolumn{8}{|c|}{ Sex: female } \\
\hline \multirow{2}{*}{$\begin{array}{l}\text { Group } \\
(\mathrm{mg} / \mathrm{kg})\end{array}$} & \multicolumn{7}{|c|}{ Body weights (kg) } \\
\hline & Animal ID & $0 \mathrm{~d}$ & $1 \mathrm{~d}$ & $3 \mathrm{~d}$ & $7 \mathrm{~d}$ & $14 \mathrm{~d}$ & Gain \\
\hline \multirow{3}{*}{$\begin{array}{l}0 \\
(n=2)\end{array}$} & 7 & 7.145 & 7.412 & 7.160 & 7.308 & 7.567 & 0.422 \\
\hline & 8 & 6.531 & 6.656 & 6.291 & 6.875 & 7.159 & 0.628 \\
\hline & Mean & $6.838 \pm 0.434$ & $7.034 \pm 0.535$ & $6.726 \pm 0.614$ & $7.092 \pm 0.306$ & $7.363 \pm 0.288$ & $0.525 \pm 0.146$ \\
\hline \multirow{3}{*}{$\begin{array}{l}1,000 \\
(n=2)\end{array}$} & 9 & 7.433 & 7.465 & 7.417 & 7.395 & 7.307 & -0.126 \\
\hline & 10 & 7.046 & 6.474 & 6.658 & 6.660 & 6.930 & -0.116 \\
\hline & Mean & $7.240 \pm 0.274$ & $6.970 \pm 0.701$ & $7.038 \pm 0.537$ & $7.028 \pm 0.520$ & $7.119 \pm 0.267$ & $-0.121 \pm 0.007$ \\
\hline \multirow{3}{*}{$\begin{array}{l}2,000 \\
(n=2)\end{array}$} & 11 & 7.449 & 7.138 & 7.238 & 7.245 & 7.534 & 0.085 \\
\hline & 12 & 7.096 & 6.898 & 7.111 & 7.007 & 7.156 & 0.060 \\
\hline & Mean & $7.273 \pm 0.250$ & $7.018 \pm 0.170$ & $7.175 \pm 0.090$ & $7.126 \pm 0.168$ & $7.345 \pm 0.267$ & $0.072 \pm 0.018$ \\
\hline
\end{tabular}

TABLe 5: Gross findings of beagle dogs orally treated with Polygala tenuifolia extracts in single dose oral toxicity study.

\begin{tabular}{|c|c|c|c|c|}
\hline \multicolumn{5}{|c|}{ Sex: male } \\
\hline \multirow{2}{*}{$\begin{array}{l}\text { Group } \\
(\mathrm{mg} / \mathrm{kg})\end{array}$} & \multicolumn{2}{|c|}{ Gross observation } & \multicolumn{2}{|c|}{ Frequency } \\
\hline & Location & Gross findings & Death & Survivors \\
\hline 0 & & No gross findings & ${ }^{*} 0 / 0$ & $2 / 2$ \\
\hline \multirow[t]{2}{*}{1,000} & & No gross findings & $0 / 0$ & $2 / 2$ \\
\hline & & No gross findings & $0 / 0$ & $0 / 2$ \\
\hline \multirow[t]{2}{*}{2,000} & Duodenum & Hemorrhage on mucous membrane & $0 / 0$ & $1 / 2$ \\
\hline & Lung & Dark red discoloration of right lobule & $0 / 0$ & $1 / 2$ \\
\hline \multirow{3}{*}{$\begin{array}{l}\text { Group } \\
(\mathrm{mg} / \mathrm{kg})\end{array}$} & \multicolumn{2}{|r|}{ Sex: female } & \multirow{2}{*}{\multicolumn{2}{|c|}{ Frequency }} \\
\hline & & tion & & \\
\hline & Location & Gross findings & Death & Survivors \\
\hline 0 & & No gross findings & ${ }^{*} 0 / 0$ & $2 / 2$ \\
\hline 1,000 & & No gross findings & $0 / 0$ & $2 / 2$ \\
\hline 2,000 & & No gross findings & $0 / 0$ & $2 / 2$ \\
\hline
\end{tabular}

${ }^{*}$ Number of animals with the sign/Number of animals examined.

As a result of the histopathological examinations on the two dead female rats from the $1,000 \mathrm{mg} / \mathrm{kg} /$ day-treated group, it was found that the rats had suffered severe postmortal changes, and therefore an accurate evaluation of the lesions was difficult. However, in rats that died on day 67 after the administration, diffuse vacuolation in the adrenal gland, atrophy of the spleen, and inflammatory cell infiltration in the heart were observed to a minor extent, and no abnormal findings were observed in a dead animal on day 50 after the administration.

\section{Discussion}

Polygala tenuifolia root is a famous traditional medicine. Although many studies have reported the pharmacological efficacy of the root extract, there is no information on its safety, such as its acute and subchronic oral toxicity. First, we investigated the acute and subchronic oral toxicity of the root extract in rats. The root extract was administered orally at 0 or $2 \mathrm{~g} / \mathrm{kg}$ body weight for the acute oral toxicity test and at $0,360,600$, or $1,000 \mathrm{mg} / \mathrm{kg}$ body weight for the subchronic oral toxicity test. In the acute oral toxicity study, one female 
TABLE 6: Food consumption of male rats.

\begin{tabular}{|c|c|c|c|c|c|c|c|c|}
\hline \multicolumn{9}{|c|}{ Food consumption (g) } \\
\hline \multirow{3}{*}{$\begin{array}{l}\text { Study: 08-RR-011 } \\
\text { Weeks }\end{array}$} & \multicolumn{4}{|c|}{ Dose (mg/kg/day) } & \multicolumn{4}{|c|}{ Sex: male } \\
\hline & 0 & & 360 & & 600 & & 1,000 & \\
\hline & Mean \pm S.D. & $N$ & Mean \pm S.D. & $N$ & Mean \pm S.D. & $N$ & Mean \pm S.D. & $N$ \\
\hline 0 & $19.69 \pm 0.65$ & 10 & $19.25 \pm 1.81$ & 10 & $19.90 \pm 1.17$ & 10 & $20.65 \pm 1.54$ & 10 \\
\hline 1 & $20.98 \pm 1.49$ & 10 & $20.96 \pm 1.26$ & 10 & $21.20 \pm 1.31$ & 10 & $20.78 \pm 1.77$ & 10 \\
\hline 2 & $19.67 \pm 1.52$ & 10 & $21.09 \pm 1.51$ & 10 & $21.00 \pm 0.74$ & 10 & $21.13 \pm 1.23$ & 10 \\
\hline 3 & $20.13 \pm 1.27$ & 10 & $21.77 \pm 1.06$ & 10 & $21.70 \pm 1.86$ & 10 & $20.44 \pm 1.13$ & 10 \\
\hline 4 & $18.60 \pm 0.80$ & 10 & $20.84 \pm 1.30^{* *}$ & 10 & $19.65 \pm 0.84$ & 10 & $19.06 \pm 0.33$ & 10 \\
\hline 5 & $19.34 \pm 0.59$ & 10 & $20.27 \pm 0.80$ & 10 & $20.26 \pm 1.66$ & 10 & $19.78 \pm 1.22$ & 10 \\
\hline 6 & $20.32 \pm 0.78$ & 10 & $20.41 \pm 1.18$ & 10 & $20.15 \pm 0.95$ & 10 & $19.02 \pm 1.41$ & 10 \\
\hline 7 & $19.72 \pm 0.44$ & 10 & $19.85 \pm 0.66$ & 10 & $19.77 \pm 0.87$ & 10 & $18.72 \pm 1.48$ & 10 \\
\hline 8 & $17.63 \pm 0.69$ & 10 & $18.61 \pm 1.56$ & 10 & $18.35 \pm 1.74$ & 10 & $18.27 \pm 1.64$ & 10 \\
\hline 9 & $19.12 \pm 1.79$ & 10 & $19.95 \pm 0.99$ & 10 & $19.05 \pm 0.56$ & 10 & $18.39 \pm 0.89$ & 10 \\
\hline 10 & $20.20 \pm 1.23$ & 10 & $21.53 \pm 1.01^{*}$ & 10 & $19.90 \pm 0.85$ & 10 & $18.97 \pm 0.61$ & 10 \\
\hline 11 & $18.17 \pm 0.41$ & 10 & $19.11 \pm 1.44$ & 10 & $18.40 \pm 1.54$ & 10 & $17.62 \pm 0.94$ & 10 \\
\hline 12 & $19.67 \pm 1.31$ & 10 & $20.64 \pm 1.35$ & 10 & $18.85 \pm 1.19$ & 10 & $19.96 \pm 2.02$ & 10 \\
\hline 13 & $20.46 \pm 1.27$ & 10 & $21.80 \pm 0.77$ & 10 & $20.61 \pm 2.73$ & 10 & $21.73 \pm 0.98$ & 10 \\
\hline
\end{tabular}

TABLE 7: Food consumption of female rats.

\begin{tabular}{|c|c|c|c|c|c|c|c|c|}
\hline \multicolumn{9}{|c|}{ Food consumption (g) } \\
\hline \multirow{3}{*}{$\begin{array}{l}\text { Study: 08-RR-011 } \\
\text { Weeks }\end{array}$} & \multicolumn{4}{|c|}{ Dose (mg/kg/day) } & \multicolumn{4}{|c|}{ Sex: female } \\
\hline & \multirow{2}{*}{$\begin{array}{c}0 \\
\text { Mean } \pm \text { S.D. }\end{array}$} & \multicolumn{3}{|c|}{360} & 600 & \multicolumn{3}{|c|}{1,000} \\
\hline & & $N$ & Mean \pm S.D. & $N$ & Mean \pm S.D. & $N$ & Mean \pm S.D. & $N$ \\
\hline 0 & $14.84 \pm 0.52$ & 10 & $14.34 \pm 1.59$ & 10 & $15.23 \pm 0.64$ & 10 & $13.08 \pm 2.94$ & 10 \\
\hline 1 & $12.75 \pm 1.17$ & 10 & $13.01 \pm 1.33$ & 10 & $13.46 \pm 1.36$ & 10 & $12.51 \pm 0.59$ & 10 \\
\hline 2 & $13.37 \pm 0.85$ & 10 & $12.28 \pm 1.35$ & 10 & $12.14 \pm 1.33$ & 10 & $11.84 \pm 2.40$ & 10 \\
\hline 3 & $13.96 \pm 0.45$ & 10 & $13.95 \pm 1.41$ & 10 & $13.91 \pm 1.06$ & 10 & $12.10 \pm 3.30$ & 10 \\
\hline 4 & $12.70 \pm 1.82$ & 10 & $12.74 \pm 0.64$ & 10 & $12.37 \pm 1.31$ & 10 & $11.52 \pm 1.82$ & 10 \\
\hline 5 & $13.72 \pm 1.89$ & 10 & $14.14 \pm 0.71$ & 10 & $12.96 \pm 2.60$ & 10 & $12.35 \pm 1.99$ & 10 \\
\hline 6 & $13.11 \pm 1.21$ & 10 & $13.40 \pm 1.55$ & 10 & $13.59 \pm 1.38$ & 10 & $11.43 \pm 1.75$ & 10 \\
\hline 7 & $13.87 \pm 0.87$ & 10 & $12.68 \pm 1.13$ & 10 & $12.16 \pm 0.51$ & 10 & $11.07 \pm 3.29$ & 10 \\
\hline 8 & $11.58 \pm 1.08$ & 10 & $12.81 \pm 1.23$ & 10 & $12.68 \pm 1.33$ & 10 & $12.75 \pm 1.06$ & 9 \\
\hline 9 & $12.44 \pm 1.24$ & 10 & $13.19 \pm 0.42$ & 10 & $12.65 \pm 1.72$ & 10 & $11.69 \pm 1.68$ & 9 \\
\hline 10 & $14.33 \pm 1.06$ & 10 & $13.49 \pm 0.81$ & 10 & $11.81 \pm 2.21$ & 10 & $12.42 \pm 1.49$ & 8 \\
\hline 11 & $13.06 \pm 1.28$ & 10 & $12.76 \pm 0.70$ & 10 & $11.64 \pm 1.12$ & 10 & $12.41 \pm 1.01$ & 8 \\
\hline 12 & $13.35 \pm 0.65$ & 10 & $13.10 \pm 1.30$ & 10 & $13.33 \pm 2.25$ & 10 & $13.15 \pm 0.91$ & 8 \\
\hline 13 & $14.33 \pm 1.19$ & 10 & $14.44 \pm 1.43$ & 10 & $13.68 \pm 2.47$ & 10 & $15.49 \pm 1.55$ & 8 \\
\hline
\end{tabular}

rat given $2 \mathrm{~g} / \mathrm{kg}$ of the root extract exhibited piloerection and decrease in activity levels 1 day after treatment and died within the same day. The gross findings of the autopsy showed no evidence of specific toxicity related to the test substance. In addition, there was a statistically significant decrease in body weight at day 1 in all test-group rats, but the body weights later recovered. Hence, this finding may show a temporary effect of the test substance. However, all rats except the aforementioned female rat were not noted in the mortality, clinical, and gross findings. These results suggest that the approximate lethal dose for the root extract of $P$. tenuifolia may be $\geq 2 \mathrm{~g} / \mathrm{kg}$ in male rats and $\leq 2 \mathrm{~g} / \mathrm{kg}$ in female rats under the conditions used in this study. In the subchronic oral toxicity study, there were no abnormal signs associated with administration of the test substance. No specific findings for body weight, consumption of food and water, ophthalmic examination, urinalyses, and blood clotting time were observed in relation to administration of the test substance. In the female group of $1,000 \mathrm{mg} / \mathrm{kg} / \mathrm{day}$, rats that died on day 50 and day 67 showed normal clinical signs, body weight changes, and consumption of food and water during the study period but demonstrated abnormal fur, dirty noses or mouths, and hypothermia the day before death. Autopsies revealed dark red coloration or diffuse red spots in the lungs, as well 
TABLE 8: Hematological values (mean \pm standard deviation) of male rats in the subchronic oral toxicity study of the root of Polygala tenuifolia.

\begin{tabular}{|c|c|c|c|c|}
\hline \multirow{2}{*}{ Parameter } & \multicolumn{4}{|c|}{ Dose (mg/kg/day) } \\
\hline & 0 & 360 & 600 & 1,000 \\
\hline $\mathrm{WBC}\left(10^{3} / \mu \mathrm{L}\right)$ & $9.83 \pm 2.83$ & $8.19 \pm 1.29$ & $8.91 \pm 2.14$ & $9.40 \pm 1.32$ \\
\hline $\operatorname{RBC}\left(10^{6} / \mu \mathrm{L}\right)$ & $8.75 \pm 0.31$ & $8.81 \pm 0.24$ & $8.69 \pm 0.33$ & $8.65 \pm 0.29$ \\
\hline Hemoglobin (g/dL) & $15.7 \pm 0.5$ & $15.7 \pm 0.4$ & $15.4 \pm 0.3$ & $15.3 \pm 0.5$ \\
\hline Hematocrit (\%) & $46.0 \pm 1.4$ & $45.5 \pm 1.0$ & $45.0 \pm 1.0$ & $44.9 \pm 1.5$ \\
\hline MCV (fL) & $52.5 \pm 1.6$ & $51.7 \pm 1.3$ & $51.8 \pm 1.6$ & $52.0 \pm 1.4$ \\
\hline $\mathrm{MCH}(\mathrm{pg})$ & $17.9 \pm 0.5$ & $17.8 \pm 0.5$ & $17.8 \pm 0.4$ & $17.7 \pm 0.4$ \\
\hline $\mathrm{MCHC}(\mathrm{g} / \mu \mathrm{L})$ & $34.1 \pm 0.3$ & $34.5 \pm 0.4$ & $34.4 \pm 0.3$ & $34.1 \pm 0.5$ \\
\hline RDW (\%) & $12.0 \pm 0.3$ & $11.8 \pm 0.3$ & $11.8 \pm 0.2$ & $11.6 \pm 0.3^{* *}$ \\
\hline HDW (g/dL) & $2.35 \pm 0.05$ & $2.35 \pm 0.08$ & $2.35 \pm 0.09$ & $2.32 \pm 0.12$ \\
\hline Platelet $\left(10^{3} / \mu \mathrm{L}\right)$ & $1061.1 \pm 106.5$ & $1030.4 \pm 59.9$ & $1043.8 \pm 38.4$ & $1103.0 \pm 64.7$ \\
\hline MPV (fL) & $7.0 \pm 0.7$ & $6.8 \pm 0.7$ & $6.8 \pm 0.7$ & $7.0 \pm 0.7$ \\
\hline Reticulocyte (\%) & $2.00 \pm 0.28$ & $1.84 \pm 0.31$ & $1.90 \pm 0.31$ & $1.83 \pm 0.18$ \\
\hline$N$ & 10 & 10 & 10 & 10 \\
\hline
\end{tabular}

WBC: white blood cell count; RBC: red blood cell count; MCV: mean corpuscular volume; MCH: mean corpuscular hemoglobin concentration; MCHC; mean corpuscular hemoglobin concentration; RDW: red cell distribution width; HDW: hemoglobin distribution width; MPV: mean platelet volume.

** Significant difference at $P<0.01$ compared with the vehicle-treated group.

TABLE 9: Hematological values (mean \pm standard deviation) of female rats in the subchronic oral toxicity study of the root of Polygala tenuifolia.

\begin{tabular}{|c|c|c|c|c|}
\hline \multirow{2}{*}{ Parameter } & \multicolumn{4}{|c|}{ Dose (mg/kg/day) } \\
\hline & 0 & 360 & 600 & 1,000 \\
\hline $\mathrm{WBC}\left(10^{3} / \mu \mathrm{L}\right)$ & $4.60 \pm 0.63$ & $4.75 \pm 0.94$ & $5.52 \pm 1.92$ & $5.11 \pm 0.79$ \\
\hline $\operatorname{RBC}\left(10^{6} / \mu \mathrm{L}\right)$ & $7.89 \pm 0.23$ & $7.98 \pm 0.36$ & $7.87 \pm 0.38$ & $7.78 \pm 0.16$ \\
\hline Hemoglobin (g/dL) & $14.3 \pm 0.6$ & $14.7 \pm 0.7$ & $14.1 \pm 0.6$ & $14.6 \pm 0.3$ \\
\hline Hematocrit (\%) & $41.2 \pm 1.3$ & $42.1 \pm 2.5$ & $40.9 \pm 1.9$ & $41.9 \pm 0.8$ \\
\hline $\mathrm{MCV}(\mathrm{fL})$ & $52.3 \pm 2.0$ & $52.8 \pm 1.1$ & $52.0 \pm 1.6$ & $53.9 \pm 1.1$ \\
\hline $\mathrm{MCH}(p g)$ & $18.2 \pm 0.9$ & $18.5 \pm 0.3$ & $18.0 \pm 0.7$ & $18.8 \pm 0.6$ \\
\hline $\mathrm{MCHC}(\mathrm{g} / \mu \mathrm{L})$ & $34.7 \pm 0.7$ & $35.0 \pm 0.4$ & $34.6 \pm 0.5$ & $34.9 \pm 0.5$ \\
\hline RDW (\%) & $10.8 \pm 0.4$ & $10.6 \pm 0.3$ & $10.8 \pm 0.4$ & $10.6 \pm 0.3$ \\
\hline HDW (g/dL) & $2.28 \pm 0.19$ & $2.22 \pm 0.13$ & $2.21 \pm 0.16$ & $2.33 \pm 0.15$ \\
\hline Platelet $\left(10^{3} / \mu \mathrm{L}\right)$ & $1104.4 \pm 103.0$ & $1166.6 \pm 89.7$ & $1194.1 \pm 166.4$ & $1134.0 \pm 88.3$ \\
\hline MPV (fL) & $6.9 \pm 0.9$ & $6.5 \pm 0.44$ & $7.0 \pm 0.9$ & $6.5 \pm 0.6$ \\
\hline Reticulocyte (\%) & $2.05 \pm 0.60$ & $1.91 \pm 0.20$ & $1.97 \pm 0.32$ & $2.08 \pm 0.46$ \\
\hline$N$ & 9 & 10 & 10 & 8 \\
\hline
\end{tabular}

WBC: white blood cell count; RBC: red blood cell count; MCV: mean corpuscular volume; MCH: mean corpuscular hemoglobin concentration; MCHC: mean corpuscular hemoglobin concentration; RDW: red cell distribution width; HDW: hemoglobin distribution width; MPV: mean platelet volume.

as diffuse red spots in the anterior stomach and thymus gland. A more accurate evaluation of the lesions was made difficult by severe postmortem changes in two rats during the histopathological studies. In the rat that died 67 days after administration of the root extract, diffuse vacuolation in the adrenal glands, atrophy of the spleen, and infiltration of the inflammatory cells in the heart were observed. In the rat that died on day 50, abnormal findings were not observed. As mentioned above, the clinical signs, body weight changes, food and water consumption, necropsy findings, and histopathological findings obtained for the dead rats did not indicate any toxicity of the test substance. Therefore, the deaths of the rats were not associated with the administration of the test substance and were judged to be accidental due to administration errors. This hypothesis is supported by the fact that no abnormal findings were observed in relation to the administration of the test substance in the remaining rats in the same dose group. We demonstrated that the test substance could be used as a food supplement, because some famous food ingredients were toxic at high doses, (e.g., lemongrass (Cymbopogon citratus) essential oil, Roystonea regia fruit, and $\alpha$-glycerylphosphorylcholine (AGPC)) [3133]. The results of the serum biochemical examinations of the rat sera revealed reductions in the levels of AST and ALT in the male groups. AST and ALT are coenzymes of pyridoxal phosphate (PALP). PALP is a derivative of vitamin $B_{6}$ and AST and ALT are activated by union with PALP, but nonlinked aminotransferases are not activated. Hence, reductions in the levels of ALT and AST occur if there is low generation of aminotransferases or PALP or if the linkage between the 
TABLE 10: Serum biochemical values (mean \pm standard deviation) of male rats in the subchronic oral dose toxicity study of the root of Polygala tenuifolia.

\begin{tabular}{|c|c|c|c|c|}
\hline \multirow{2}{*}{ Parameter } & \multicolumn{4}{|c|}{ Dose (mg/kg/day) } \\
\hline & 0 & 360 & 600 & 1,000 \\
\hline Number of animals examined & 10 & 10 & 10 & 10 \\
\hline AST (IU/L) & $105.0 \pm 26.6$ & $93.4 \pm 24.6$ & $87.9 \pm 18.5$ & $80.5 \pm 11.7$ \\
\hline $\operatorname{ALT}(\mathrm{IU} / \mathrm{L})$ & $60.1 \pm 12.7$ & $46.6 \pm 7.5$ & $44.6 \pm 6.8^{*}$ & $40.0 \pm 5.0^{* *}$ \\
\hline $\operatorname{ALP}(\mathrm{IU} / \mathrm{L})$ & $121.2 \pm 32.8$ & $104.4 \pm 29.7$ & $105.1 \pm 15.2$ & $99.5 \pm 17.5$ \\
\hline $\mathrm{BUN}(\mathrm{mg} / \mathrm{dL})$ & $18.9 \pm 3.5$ & $15.0 \pm 1.8^{*}$ & $14.6 \pm 1.4^{*}$ & $14.3 \pm 1.6^{*}$ \\
\hline CRE (mg/dL) & $0.64 \pm 0.09$ & $0.56 \pm 0.03$ & $0.54 \pm 0.04$ & $0.60 \pm 0.06$ \\
\hline GLU (mg/dL) & $139.8 \pm 18.1$ & $122.9 \pm 11.8^{* *}$ & $125.9 \pm 11.1^{*}$ & $124.1 \pm 8.8^{*}$ \\
\hline $\mathrm{CHO}(\mathrm{mg} / \mathrm{dL})$ & $127.2 \pm 38.6$ & $107.4 \pm 12.3$ & $95.2 \pm 11.7$ & $98.0 \pm 11.1$ \\
\hline PRO (g/dL) & $7.51 \pm 1.12$ & $6.56 \pm 0.18$ & $6.50 \pm 0.26$ & $6.4 \pm 0.16$ \\
\hline $\mathrm{CPK}(\mathrm{IU} / \mathrm{L})$ & $195.4 \pm 127.9$ & $141.4 \pm 96.3$ & $98.2 \pm 78.8$ & $93.3 \pm 68.6$ \\
\hline $\mathrm{ALB}(\mathrm{g} / \mathrm{dL})$ & $3.51 \pm 0.43$ & $3.25 \pm 0.08$ & $3.24 \pm 0.12$ & $3.24 \pm 0.09$ \\
\hline BIL (mg/dL) & $0.22 \pm 0.02$ & $0.20 \pm 0.02$ & $0.20 \pm 0.02$ & $0.20 \pm 0.01$ \\
\hline $\mathrm{TG}(\mathrm{mg} / \mathrm{dL})$ & $60.8 \pm 16.8$ & $57.2 \pm 9.8$ & $53.7 \pm 6.7$ & $63.2 \pm 15.0$ \\
\hline $\mathrm{IP}(\mathrm{mg} / \mathrm{dL})$ & $8.42 \pm 1.56$ & $6.92 \pm 0.21$ & $7.18 \pm 0.63$ & $7.49 \pm 0.34$ \\
\hline $\mathrm{Ca}^{2+}(\mathrm{mg} / \mathrm{dL})$ & $11.81 \pm 1.75$ & $10.11 \pm 0.15$ & $10.18 \pm 0.23$ & $10.13 \pm 0.28$ \\
\hline A/G (ratio) & $0.89 \pm 0.07$ & $0.99 \pm 0.03^{* *}$ & $1.00 \pm 0.04^{* *}$ & $1.02 \pm 0.04^{* *}$ \\
\hline $\mathrm{Na}^{+}(\mathrm{mmol} / \mathrm{L})$ & $140.5 \pm 4.22$ & $144.5 \pm 1.08^{* *}$ & $144.4 \pm 1.07^{* *}$ & $143.9 \pm 0.74^{* *}$ \\
\hline $\mathrm{K}^{+}(\mathrm{mmol} / \mathrm{L})$ & $4.39 \pm 0.15$ & $4.47 \pm 0.27$ & $4.50 \pm 0.25$ & $4.49 \pm 0.15$ \\
\hline $\mathrm{Cl}^{-}(\mathrm{mmol} / \mathrm{L})$ & $104.2 \pm 2.97$ & $107.4 \pm 0.84^{* *}$ & $107.6 \pm 0.7^{* *}$ & $107.3 \pm 0.82^{* *}$ \\
\hline $\bar{N}$ & 10 & 10 & 10 & 10 \\
\hline
\end{tabular}

TABLE 11: Serum biochemical values (mean \pm standard deviation) of female rats in the subchronic oral dose toxicity study of the root of Polygala tenuifolia.

\begin{tabular}{|c|c|c|c|c|}
\hline \multirow{2}{*}{ Parameter } & \multicolumn{4}{|c|}{ Dose (mg/kg/day) } \\
\hline & 0 & 360 & 600 & 1,000 \\
\hline Number of animals examined & 10 & 10 & 10 & 10 \\
\hline AST (IU/L) & $91.1 \pm 14.0$ & $94.0 \pm 17.8$ & $85.9 \pm 16.7$ & $86.8 \pm 14.0$ \\
\hline ALT (IU/L) & $35.5 \pm 5.8$ & $34.5 \pm 4.1$ & $32.9 \pm 5.1$ & $32.6 \pm 5.3$ \\
\hline $\operatorname{ALP}(\mathrm{IU} / \mathrm{L})$ & $64.1 \pm 14.9$ & $74.8 \pm 9.9$ & $73.8 \pm 20.8$ & $71.2 \pm 10.1$ \\
\hline BUN (mg/dL) & $19.3 \pm 3.0$ & $17.2 \pm 1.9$ & $17.4 \pm 1.9$ & $18.4 \pm 1.6$ \\
\hline CRE (mg/dL) & $0.65 \pm 0.07$ & $0.64 \pm 0.06$ & $0.66 \pm 0.11$ & $0.67 \pm 0.09$ \\
\hline GLU (mg/dL) & $116.2 \pm 12.7$ & $119.2 \pm 11.6$ & $111.7 \pm 7.3$ & $110.4 \pm 11.0$ \\
\hline $\mathrm{CHO}(\mathrm{mg} / \mathrm{dL})$ & $97.2 \pm 17.7$ & $106.3 \pm 16.7$ & $112.9 \pm 19.4$ & $120.4 \pm 15.1$ \\
\hline PRO (g/dL) & $6.23 \pm 0.15$ & $6.36 \pm 0.29$ & $6.23 \pm 0.32$ & $6.11 \pm 0.19$ \\
\hline CPK (IU/L) & $134.8 \pm 60.9$ & $120.2 \pm 84.3$ & $115.9 \pm 82.1$ & $121.9 \pm 63.4$ \\
\hline $\operatorname{ALB}(\mathrm{g} / \mathrm{dL})$ & $3.23 \pm 0.09$ & $3.31 \pm 0.15$ & $3.26 \pm 0.15$ & $3.20 \pm 0.12$ \\
\hline BIL (mg/dL) & $0.20 \pm 0.02$ & $0.21 \pm 0.02$ & $0.21 \pm 0.03$ & $0.21 \pm 0.02$ \\
\hline $\mathrm{TG}(\mathrm{mg} / \mathrm{dL})$ & $43.9 \pm 5.2$ & $42.9 \pm 7.5$ & $52.8 \pm 16.3$ & $47.8 \pm 8.3$ \\
\hline IP (mg/dL) & $6.00 \pm 0.85$ & $6.15 \pm 1.22$ & $6.42 \pm 0.99$ & $6.46 \pm 0.45$ \\
\hline $\mathrm{Ca}^{2+}(\mathrm{mg} / \mathrm{dL})$ & $9.61 \pm 0.13$ & $9.78 \pm 0.46$ & $9.71 \pm 0.17$ & $9.63 \pm 0.15$ \\
\hline A/G (ratio) & $1.08 \pm 0.05$ & $1.09 \pm 0.08$ & $1.10 \pm 0.07$ & $1.11 \pm 0.08$ \\
\hline $\mathrm{Na}^{+}(\mathrm{mmol} / \mathrm{L})$ & $143.3 \pm 1.06$ & $143.6 \pm 0.97$ & $142.7 \pm 1.06$ & $142.5 \pm 1.20$ \\
\hline $\mathrm{K}^{+}(\mathrm{mmol} / \mathrm{L})$ & $4.24 \pm 0.19$ & $4.57 \pm 1.25$ & $4.15 \pm 0.27$ & $4.24 \pm 0.18$ \\
\hline $\mathrm{Cl}^{-}(\mathrm{mmol} / \mathrm{L})$ & $108.3 \pm 1.16$ & $109.1 \pm 1.20$ & $109.6 \pm 0.84$ & $109.88 \pm 1.64$ \\
\hline$N$ & 10 & 10 & 10 & 8 \\
\hline
\end{tabular}


TABle 12: Absolute and relative organ weight of males in the subchronic oral dose toxicity study of the root of Polygala tenuifolia.

\begin{tabular}{|c|c|c|c|c|}
\hline \multirow{2}{*}{ Parameter } & \multicolumn{4}{|c|}{ Dose (mg/kg/day) } \\
\hline & 0 & 360 & 600 & 1,000 \\
\hline Body weight & $444.51 \pm 22.61$ & $460.88 \pm 39.59$ & $450.34 \pm 30.11$ & $437.99 \pm 19.81$ \\
\hline Adrenal gland, left & $0.0304 \pm 0.0048$ & $0.0282 \pm 0.0039$ & $0.0295 \pm 0.0038$ & $0.0300 \pm 0.0045$ \\
\hline Per body weight (\%) & $0.0069 \pm 0.0011$ & $0.0061 \pm 0.0007$ & $0.0065 \pm 0.0006$ & $0.0068 \pm 0.0010$ \\
\hline Adrenal gland, right & $0.0292 \pm 0.0045$ & $0.0285 \pm 0.0039$ & $0.0288 \pm 0.0035$ & $0.0284 \pm 0.0042$ \\
\hline Per body weight (\%) & $0.0066 \pm 0.0011$ & $0.0062 \pm 0.0009$ & $0.0064 \pm 0.0006$ & $0.0065 \pm 0.0009$ \\
\hline Pituitary gland & $0.0143 \pm 0.0031$ & $0.0131 \pm 0.0013$ & $0.0126 \pm 0.0018$ & $0.0130 \pm 0.0032$ \\
\hline Per body weight (\%) & $0.0032 \pm 0.0006$ & $0.0028 \pm 0.0002$ & $0.0028 \pm 0.0003$ & $0.0030 \pm 0.0007$ \\
\hline Thymus & $0.2515 \pm 0.0423$ & $0.3159 \pm 0.0400^{* *}$ & $0.3294 \pm 0.0524^{* *}$ & $0.2891 \pm 0.0583$ \\
\hline Per body weight (\%) & $0.0570 \pm 0.0115$ & $0.0686 \pm 0.0067^{*}$ & $0.0734 \pm 0.0120^{* *}$ & $0.0660 \pm 0.0132$ \\
\hline Prostate & $0.5877 \pm 0.1284$ & $0.5855 \pm 0.1785$ & $0.5839 \pm 0.1195$ & $0.6297 \pm 0.1285$ \\
\hline Per body weight (\%) & $0.1330 \pm 0.0325$ & $0.1278 \pm 0.0404$ & $0.1289 \pm 0.0196$ & $0.1436 \pm 0.0280$ \\
\hline Testis, left & $2.9152 \pm 0.1365$ & $2.0512 \pm 0.1353$ & $2.0208 \pm 0.1221$ & $2.0452 \pm 0.1618$ \\
\hline Per body weight (\%) & $0.4546 \pm 0.0383$ & $0.4473 \pm 0.0410$ & $0.4495 \pm 0.0245$ & $0.4667 \pm 0.0251$ \\
\hline Testis, left & $2.0112 \pm 0.1409$ & $2.0550 \pm 0.1629$ & $2.0063 \pm 0.1262$ & $2.0337 \pm 0.1905$ \\
\hline Per body weight (\%) & $0.4539 \pm 0.0414$ & $0.4484 \pm 0.0486$ & $0.4464 \pm 0.0278$ & $0.4636 \pm 0.0269$ \\
\hline Epididymis, left & $0.6852 \pm 0.0348$ & $0.6768 \pm 0.0397$ & $0.6403 \pm 0.0492$ & $0.6961 \pm 0.0583$ \\
\hline Per body weight (\%) & $0.1546 \pm 0.0108$ & $0.1474 \pm 0.0093$ & $0.1423 \pm 0.0085$ & $0.1590 \pm 0.0119$ \\
\hline Epididymis, right & $0.7013 \pm 0.0830$ & $0.6667 \pm 0.0476$ & $0.6459 \pm 0.0381$ & $0.6834 \pm 0.0461$ \\
\hline Per body weight (\%) & $0.1580 \pm 0.0177$ & $0.1452 \pm 0.0113$ & $0.1436 \pm 0.0057$ & $0.1561 \pm 0.0103$ \\
\hline Spleen & $0.8944 \pm 0.2307$ & $0.8399 \pm 0.0698$ & $0.8576 \pm 0.1300$ & $0.8627 \pm 0.0864$ \\
\hline Per body weight (\%) & $0.2019 \pm 0.0562$ & $0.1828 \pm 0.0154$ & $0.1899 \pm 0.0215$ & $0.1969 \pm 0.0173$ \\
\hline Kidney, left & $1.3475 \pm 0.1109$ & $1.3537 \pm 0.1786$ & $1.3185 \pm 0.1704$ & $1.2721 \pm 0.1128$ \\
\hline Per body weight (\%) & $0.3032 \pm 0.0174$ & $0.2930 \pm 0.0189$ & $0.2923 \pm 0.0259$ & $0.2903 \pm 0.0190$ \\
\hline Kidney, right & $1.3439 \pm 0.1324$ & $1.3803 \pm 0.1793$ & $1.3786 \pm 0.1808$ & $1.2969 \pm 0.1078$ \\
\hline Per body weight (\%) & $0.3020 \pm 0.0167$ & $0.2989 \pm 0.0216$ & $0.3057 \pm 0.0274$ & $0.2960 \pm 0.0180$ \\
\hline Heart & $1,3823 \pm 0.1325$ & $1.5006 \pm 0.1825$ & $1.5012 \pm 0.1357$ & $1.4132 \pm 0.1456$ \\
\hline Per body weight (\%) & $0.3017 \pm 0.0197$ & $0.3252 \pm 0.0241$ & $0.3333 \pm 0.0200$ & $0.3225 \pm 0.0271$ \\
\hline Lung & $1.9149 \pm 0.1630$ & $1.8571 \pm 0.1483$ & $1.8949 \pm 0.1652$ & $1.8769 \pm 0.1039$ \\
\hline Per body weight (\%) & $0.4314 \pm 0.0363$ & $0.4043 \pm 0.0327$ & $0.4211 \pm 0.0302$ & $0.4288 \pm 0.0210$ \\
\hline Brain & $2.0127 \pm 0.0602$ & $1.9798 \pm 0.0874$ & $2.0014 \pm 0.0659$ & $1.9522 \pm 0.0843$ \\
\hline Per body weight (\%) & $0.4539 \pm 0.0237$ & $0.4313 \pm 0.0254$ & $0.4457 \pm 0.0248$ & $0.4459 \pm 0.0135$ \\
\hline Liver & $11.7210 \pm 1.0504$ & $11.5963 \pm 1.1787$ & $11.4193 \pm 1.1750$ & $11.2844 \pm 0.0850$ \\
\hline Per body weight (\%) & $2.6348 \pm 0.1369$ & $2.5149 \pm 0.1118$ & $2.5319 \pm 0.1342$ & $2.5752 \pm 0.1174$ \\
\hline$N$ & 10 & 10 & 10 & 10 \\
\hline
\end{tabular}

Body weight before necropsy and after fasting.

${ }^{* / *}$ Significant difference at $P<0.05 / 0.01$ compared with the vehicle-treated group.

aminotransferases and PALP is disturbed. Cephalosporinlike antibiotics are known to induce reductions in ALT levels, but in toxicity studies, reductions have been mentioned in general and toxicological significance has not been attributed $[34,35]$. The blood urea nitrogen (BUN) levels in the blood represent the nitrogen content in relation to urea, which is a metabolite of nitrogen and is closely related to heart diseases. The BUN value might show a decrease, due to a reduction in urea synthesis during toxic hepatitis, severe hepatic impairment, and consuming a low protein diet. However, in the present study, no abnormal findings related to dose were observed. In general, the decrease in BUN level is not a critical factor in toxicity studies [34]. Moreover, these changes were not regarded as adverse effects because they remained within normal ranges $[36,37]$. Hematological examinations revealed reductions in red blood cell volume distribution width (RDW) in the male group given $1,000 \mathrm{mg} / \mathrm{kg} / \mathrm{day}$. Decreasing tendencies in the levels of GLU, ALP, CHO, PRO, ALB, and CPK and increments in the levels of $A / G, \mathrm{Na}^{+}$, and $\mathrm{Cl}^{-}$in male treatment groups were within the normal range $[38,39]$ and also remained within the normal range when compared with the historical data [21] available at ChemOn Inc. In the vehicle-treated group, increments or reductions in some measurement items were also observed accidentally and were thought to be somewhat contributory to the above results [40]; therefore, it was considered that these changes were toxicological and were not associated with the administration of the test substance. RDW decreased 
TABLE 13: Absolute and relative organ weight of females in the subchronic oral dose toxicity study of the root of Polygala tenuifolia.

\begin{tabular}{|c|c|c|c|c|}
\hline \multirow{2}{*}{ Parameter } & \multicolumn{4}{|c|}{ Dose (mg/kg/day) } \\
\hline & 0 & 360 & 600 & 1,000 \\
\hline Body weight & $260.11 \pm 15.83$ & $259.59 \pm 6.80$ & $253.95 \pm 17.41$ & $250.61 \pm 7.87$ \\
\hline Ovary, left (g) & $0.0505 \pm 0.0119$ & $0.0547 \pm 0.0081$ & $0.0467 \pm 0.0138$ & $0.0537 \pm 0.0067$ \\
\hline Per body weight (\%) & $0.0193 \pm 0.0040$ & $0.0211 \pm 0.0031$ & $0.0183 \pm 0.0045$ & $0.0214 \pm 0.0025$ \\
\hline Ovary, right & $0.0532 \pm 0.0072$ & $0.0526 \pm 0.0064$ & $0.0515 \pm 0.0092$ & $0.0538 \pm 0.0058$ \\
\hline Per body weight (\%) & $0.0204 \pm 0.0025$ & $0.0203 \pm 0.0026$ & $0.0203 \pm 0.0032$ & $0.0215 \pm 0.0024$ \\
\hline Adrenal gland, left & $0.0332 \pm 0.0073$ & $0.0339 \pm 0.0030$ & $0.0324 \pm 0.0052$ & $0.0370 \pm 0.0041$ \\
\hline Per body weight (\%) & $0.0128 \pm 0.0025$ & $0.0131 \pm 0.0010$ & $0.0128 \pm 0.0020$ & $0.0148 \pm 0.0019$ \\
\hline Adrenal gland, right & $0.0279 \pm 0.0044$ & $0.0309 \pm 0.0046$ & $0.0301 \pm 0.0036$ & $0.0319 \pm 0.0068$ \\
\hline Per body weight (\%) & $0.0107 \pm 0.0016$ & $0.0119 \pm 0.0017$ & $0.0119 \pm 0.30015$ & $0.0128 \pm 0.0029$ \\
\hline Pituitary gland & $0.0148 \pm 0.0053$ & $0.0137 \pm 0.0011$ & $0.0134 \pm 0.0015$ & $0.0141 \pm 0.0019$ \\
\hline Per body weight (\%) & $0.0056 \pm 0.0016$ & $0.0053 \pm 0.0004$ & $0.0053 \pm 0.0004$ & $0.0056 \pm 0.0009$ \\
\hline Thymus & $0.2235 \pm 0.0323$ & $0.2292 \pm 0.0349$ & $0.2243 \pm 0.0232$ & $0.2290 \pm 0.0320$ \\
\hline Per body weight (\%) & $0.0863 \pm 0.0142$ & $0.0882 \pm 0.0127$ & $0.0883 \pm 0.0068$ & $0.0915 \pm 0.0128$ \\
\hline Uterus & $0.6040 \pm 0.1695$ & $0.5195 \pm 0.1438$ & $0.4848 \pm 0.1573$ & $0.6109 \pm 0.3313$ \\
\hline Per body weight (\%) & $0.2347 \pm 0.0730$ & $0.2002 \pm 0.0548$ & $0.1929 \pm 0.0678$ & $0.2436 \pm 0.1313$ \\
\hline Spleen & $0.5954 \pm 0.596$ & $0.5786 \pm 0.0512$ & $0.5402 \pm 0.1754$ & $0.6280 \pm 0.3671$ \\
\hline Per body weight (\%) & $0.2287 \pm 0.0147$ & $0.2228 \pm 0.0174$ & $0.2111 \pm 0.0673$ & $0.2506 \pm 0.1340$ \\
\hline Kidney, left & $0.7683 \pm 0.0657$ & $0.7544 \pm 0.0510$ & $0.7713 \pm 0.1081$ & $0.7513 \pm 0.4212$ \\
\hline Per body weight (\%) & $0.2953 \pm 0.0162$ & $0.2905 \pm 0.0164$ & $0.3049 \pm 0.0495$ & $0.3000 \pm 0.1856$ \\
\hline Kidney, right & $0.7547 \pm 0.0548$ & $0.7553 \pm 0.0511$ & $0.7900 \pm 0.1248$ & $0.7618 \pm 0.4748$ \\
\hline Per body weight (\%) & $0.2898 \pm 0.0117$ & $0.2909 \pm 0.0178$ & $0.3124 \pm 0.0572$ & $0.3041 \pm 0.1993$ \\
\hline Heart & $0.9126 \pm 0.0678$ & $0.8911 \pm 0.0619$ & $0.9117 \pm 0.1012$ & $0.9030 \pm 0.6912$ \\
\hline Per body weight (\%) & $0.3511 \pm 0.0197$ & $0.3433 \pm 0.0225$ & $0.3588 \pm 0.0280$ & $0.3607 \pm 0.3053$ \\
\hline Lung & $1.4077 \pm 0.0881$ & $1.4371 \pm 0.0983$ & $1.4229 \pm 0.2161$ & $1.4301 \pm 0.9812$ \\
\hline Per body weight (\%) & $0.5418 \pm 0.0275$ & $0.5535 \pm 0.0329$ & $0.5628 \pm 0.1006$ & $0.5704 \pm 0.3008$ \\
\hline Brain & $1.8129 \pm 0.0649$ & $1.8308 \pm 0.0685$ & $1.8026 \pm 0.0750$ & $1.8440 \pm 0.5932$ \\
\hline Per body weight (\%) & $0.6982 \pm 0.0274$ & $0.7058 \pm 0.0358$ & $0.7123 \pm 0.0485$ & $0.7367 \pm 0.3932$ \\
\hline Liver & $6.0596 \pm 0.2314$ & $6.3790 \pm 0.6585$ & $6.4577 \pm 0.5182$ & $6.4618 \pm 0.4515$ \\
\hline Per body weight (\%) & $2.3339 \pm 0.0996$ & $2.4553 \pm 0.2191$ & $2.5459 \pm 0.1755$ & $2.5778 \pm 0.1469^{*}$ \\
\hline$N$ & 10 & 10 & 10 & 8 \\
\hline
\end{tabular}

Body weight before necropsy and after fasting.

${ }^{*}$ Significant difference at $P<0.05$ compared with the vehicle-treated group.

significantly, but the changes remained within the limits of normal biological variations [41, 42]. Significant changes in the absolute/relative weights of the thymus gland in the male groups given 360 and $600 \mathrm{mg} / \mathrm{kg} / \mathrm{day}$, the relative weights of the left epididymis in the male groups given $600 \mathrm{mg} / \mathrm{kg} / \mathrm{day}$, and the relative weights of the liver in the female group given $1,000 \mathrm{mg} / \mathrm{kg} /$ day were not accompanied by abnormal autopsy or histopathological findings. A relationship with sex or dose was not observed, so these changes were not considered to be a toxicological feature of the test substance. Even though the weights of the thymus gland and left epididymis changed significantly, they were within the limits of normal biological variations; this finding was in accordance with results reported by Wang et al. [43]. Regarding relative organ weight, an increase in the liver in the female rats, compared with Banpungtongseong-san reported organ weights analysis, showed that there were statistically significant changes in the absolute weights of the thymus in the male group of $2,000 \mathrm{mg} / \mathrm{kg} /$ day. However, these changes were not regarded as adverse effects because they were minor, remained within normal historical control ranges for Fischer 344 rats, and were not correlated with pathological lesions in the respective organs $[44,45]$. Autopsy and histopathological examinations revealed abnormal findings in some organs, but the prevalence of these findings was low and these changes were spontaneous and nonspecific [46, 47]. Therefore, the toxicological importance of these findings was negligible. No abnormal findings were observed in association with administration of the test substance upon histopathological examination of abnormal organs in low- and medium-dose groups.

Second, acute oral toxicity of the root extract $P$. tenuifolia in beagle dogs was investigated. The root extract was administered orally at 1,000 or $2,000 \mathrm{mg} / \mathrm{kg}$ body weights; the vehicle-treated group was only given gelatin capsules for the single dose oral toxicity test. As a result of the present 
study, vomiting and inhibition of body weight gain were observed after the administration of the test substance, but other abnormalities in clinical signs, deaths, and abnormal findings in the necropsy results were not observed in relation to administration of the test substance. The results of clinical sign examinations of the dogs observed vomiting in one male given $1,000 \mathrm{mg} / \mathrm{kg}$ at $5 \mathrm{hr}$ and in one male given $2,000 \mathrm{mg} / \mathrm{kg}$ on day 5 . This was after the administration was considered to be unrelated to the test substance because vomiting was also observed in the vehicle-treated female group on day 1 , and vomiting like this is commonly observed in dogs which have a well-developed vomiting system. However, these changes were not considered serious when compared with the previous study, as some famous oriental medicine and food compositions were found to be toxic, including Paecilomyces sinclairii [48], SH21-B [49], epigallocatechin gallate (EGCG) [50], novel thiazolidinedione (MCC-555) [51], and nelumbinis semen (NS, the seeds of Nelumbo nucifera) [52]. Vomiting of the food occurred sporadically in some dogs in all groups, including the controls. This frequency was typical for this colony of dogs [53]. In general, the incidence of vomiting did not suggest an effect of the test substance [54]. Vomiting is a common presenting sign in small animal practice [55]. Moreover, many peripheral stimuli of abdominal structures will initiate vomiting in dogs $[56,57]$. The "chemoreceptor trigger zone" of the brainstem has been identified as the area postrema that is located on the dorsal surface of the medulla oblongata adjacent to the caudal end of the fourth ventricle [58]. Therefore, it was not considered to be related to the treatment with the test substance. The loss of body weight was observed in males and females, but because vomiting of the test substance occurred more frequently at $2,000 \mathrm{mg} / \mathrm{kg}$ than at $1,000 \mathrm{mg} / \mathrm{kg}$, the absorption of test substance seemed to be relatively higher at $1,000 \mathrm{mg} / \mathrm{kg}$ than at $2,000 \mathrm{mg} / \mathrm{kg}$. Also, the loss of body weight showed a temporary serious tendency on days 1 and 3 after the administration. However, the body weights of the male $1,000 \mathrm{mg} / \mathrm{kg}$ and $2,000 \mathrm{mg} / \mathrm{kg}$ groups recovered. In addition, the vehicle-treated group of females showed a tendency to decrease in body weight from approximately 14 days. In all groups, increment and reduction tendencies were also observed, and these changes were observed [5962]. The changes in body weights were probably the result of irritation of the alimentary tract [61]. We also considered gastroenteric issues from vomiting as accordingly inducing a disorder of the nutriments absorption [63]. A hemorrhage of the mucosa of the duodenum and the dark discoloration of the lung observed in a male given $2,000 \mathrm{mg} / \mathrm{kg}$ were not considered as test substance-related changes, because these were occasionally found in domestic beagle dogs without administration of any of the test substances. Dog experiment findings were generally observed as environmental causes, because these results are ignored [64]. In the necropsy results, a dark red spot on the lung and a light gray color change were observed. However, this change was not dose-related [49], but it was an accidental change. Also, the lungs showed discoloration (dark, mottled, and focus), and the stomach showed discoloration $[65,66]$. The gross lesion of the mass or nodule corresponded to the microscopic lesion of the thrombus. These were direct effects of the drug or were secondary to the vascular damage caused by dehydration (with hemodynamic shock) from vomiting and diarrhea [66]. Histopathology changes and hemorrhages in the lung were observed by Werley et al. [67]. However, they were considered to be typical of spontaneously arising background findings, and no other biologically significant effects were observed by histopathology studies on the tissues and organs. The discolorations in the other various organs and tissues were within the range of normal background lesions in dogs of this strain and age and were therefore not considered to be related to the test substance [68].

In this experiment, the administration of the root extract of Polygala tenuifolia Willdenow ( $2 \mathrm{~g} / \mathrm{kg} /$ day) did not result in acute oral toxicity in the SD rats. The minimum lethal dose (MLD) was also considered to be higher than $1,000 \mathrm{mg} / \mathrm{kg}$, since vomiting of the test substance occurred at 2,000 mg/kg. In the subchronic oral toxicity test, no obvious toxic changes due to administration of the root extract of $P$. tenuifolia were observed in any of the parameters tested (clinical signs, mortality, body weight changes, food and water consumption, ophthalmic examination, urinalyses, hematology, serum biochemistry, organ weights, autopsy, and histopathology). Therefore, under the experimental conditions, the noobserved-adverse-effect level (NOAEL) of the root extract of $P$. tenuifolia was determined to be $1,000 \mathrm{mg} / \mathrm{kg} / \mathrm{day}$ for both sexes, but the target organ was not established. In conclusion, the present study demonstrated that the acute or subchronic toxicity of the root extract of Polygala tenuifolia was not toxic in rats and beagle dogs.

\section{Conflict of Interests}

The authors of this paper have no conflict of interests.

\section{Acknowledgments}

The collection, analysis, and interpretation of data of the acute toxicity and the subchronic toxicity were supported by SNUH-GLP (Non-Clinical Research Center, Biomedical Research Institute, Seoul National University Hospital) and Preclinical Research Center, ChemOn Inc., respectively.

\section{References}

[1] W.-Y. Jiang, "Therapeutic wisdom in traditional Chinese medicine: a perspective from modern science," Trends in Pharmacological Sciences, vol. 26, no. 11, pp. 558-563, 2005.

[2] S. Liu, L.-Z. Yi, and Y.-Z. Liang, "Traditional Chinese medicine and separation science," Journal of Separation Science, vol. 31, no. 11, pp. 2113-2137, 2008.

[3] J.-L. Tang, B.-Y. Liu, and K.-W. Ma, "Traditional Chinese medicine," The Lancet, vol. 372, no. 9654, pp. 1938-1940, 2008.

[4] C.-F. Chau and S.-H. Wu, "The development of regulations of Chinese herbal medicines for both medicinal and food uses," Trends in Food Science \& Technology, vol. 17, no. 6, pp. 313-323, 2006.

[5] K. Chan and L. Cheung, "Examples of interactions between Chinese herbal medicinal products and orthodox drug," in 
Interactions between Chinese Herbal Medicinal Products and Orthodox Drugs, pp. 57-97, Harwood Academic Publishers, Amsterdam, The Netherlands, 2000.

[6] A. N. Ukwuani, M. G. Abubakar, S. W. Hassan, and B. M. Agaie, "Toxicological studies of hydromethanolic leaves extract of Grewia crenata," International Journal of Pharmaceutical Sciences and Drug Research, vol. 4, pp. 245-249, 2012.

[7] T. Nagai, Y. Suzuki, H. Kiyohara et al., "Onjisaponins, from the root of Polygala tenuifolia Willdenow, as effective adjuvants for nasal influenza and diphtheria-pertussis-tetanus vaccines," Vaccine, vol. 19, no. 32, pp. 4824-4834, 2001.

[8] L. C. Klein Jr., S. Faloni de Andrade, and V. C. Filho, "A pharmacognostic approach to the polygala genus: phytochemical and pharmacological aspects," Chemistry and Biodiversity, vol. 9, no. 2, pp. 181-209, 2012.

[9] Z. L. Jin, N. Gao, D. Zhou, M. G. Chi, X. M. Yang, and J. P. Xu, "The extracts of Fructus Akebiae, a preparation containing 90\% of the active ingredient hederagenin: Serotonin, norepinephrine and dopamine reuptake inhibitor," Pharmacology Biochemistry and Behavior, vol. 100, no. 3, pp. 431-439, 2012.

[10] K. C. Huang, The Pharmacology of Chinese Herbs, CRC Press, Boca Raton, Fla, USA, 1993.

[11] P. Liu, Y. Hu, D.-H. Guo et al., "Potential antidepressant properties of Radix Polygalae (Yuan Zhi)," Phytomedicine, vol. 17, no. 10, pp. 794-799, 2010.

[12] C. H. Park, S. H. Choi, J.-W. Koo et al., "Novel cognitive improving and neuroprotective activities of Polygala Tenuifolia willdenow extract, BT-11," Journal of Neuroscience Research, vol. 70, no. 3, pp. 484-492, 2002.

[13] J.-Y. Lee, K. Y. Kim, K. Y. Shin, B. Y. Won, H. Y. Jung, and Y.-H. Suh, "Effects of BT-11 on memory in healthy humans," Neuroscience Letters, vol. 454, no. 2, pp. 111-114, 2009.

[14] K. Y. Shin, B. Y. Won, C. Heo et al., "BT-11 improves stressinduced memory impairments through increment of glucose utilization and total neural cell adhesion molecule levels in rat brains," Journal of Neuroscience Research, vol. 87, no. 1, pp. 260268, 2009.

[15] K. Y. Shin, J.-Y. Lee, B. Y. Won et al., "BT-11 is effective for enhancing cognitive functions in the elderly humans," Neuroscience Letters, vol. 465, no. 2, pp. 157-159, 2009.

[16] Y. Ikeya, S. Takeda, M. Tunakawa et al., "Cognitive improving and cerebral protective effects of acylated oligosaccharides in Polygala tenuifolia," Biological and Pharmaceutical Bulletin, vol. 27, no. 7, pp. 1081-1085, 2004.

[17] Y. Ling, Z. Li, M. Chen, Z. Sun, M. Fan, and C. Huang, "Analysis and detection of the chemical constituents of Radix Polygalae and their metabolites in rats after oral administration by ultra high-performance liquid chromatography coupled with electrospray ionization quadrupole time-of-flight tandem mass spectrometry," Journal of Pharmaceutical and Biomedical Analysis, vol. 85, pp. 1-13, 2013.

[18] Y. J. Chen, X. B. Huang, Z. X. Li et al., "Tenuigeninprotes cultured hippocampal neurons against methlglyoxal-induced neurotoxicity," European Journal of Pharmacology, vol. 645, pp. $1-8,2010$.

[19] Y. Chen, X. Huang, W. Chen, N. Wang, and L. Li, “Tenuigenin promotes proliferation and differentiation of hippocampal neural stem cells," Neurochemical Research, vol. 37, no. 4, pp. 771$777,2012$.

[20] OECD, OECD Principles of Good Laboratory Practice ENV/MC/CHEM (98) 17, OECD, Paris, France, 1998.
[21] OECD, Guidelines for Testing of Chemicals, Guidline 408, Repeated Dose 90-day Oral Toxicity Study in Rodents, OECD, Paris, France, 1998.

[22] KFDA, "Good Laboratory Practice Regulation for Non-Clinical Laboratory Studies," (Notification No. 2009-102), KFDA, 2009.

[23] KFDA, The Standards of Toxicity Study for Medicinal Products (Notification No. 2009-116), KFDA, Seoul, Republic of Korea, 2009.

[24] G. W. Snedecor and W. G. Cochran, "One way classifications; analysis of variance," in Statistical Methods, pp. 215-237, Thelowa state University Press, Ames, Iowa, USA, 7th edition, 1980.

[25] H. Levene, "In contributions to probability and statistics," in Essays in Honor of Harold Hotelling, I. Olkin, S. G. Ghurye, W. Hoeffding et al., Eds., pp. 278-292, Stanford University Press, 1960.

[26] D. B. Duncan, "Multiple range and multiple F tests," Biometrics, vol. 11, pp. 1-42, 1955.

[27] H. Scheffe, "A method for judging all contrasts in the analysis of variance," Biometrika, vol. 40, no. 1-2, pp. 87-104, 1953.

[28] C. W. Dunnett, "New tables for multiple comparisons with a control," Biometrics, vol. 20, pp. 482-491, 1964.

[29] W. H. Kruskal and W. A. Wallis, "Use of ranks in onecriterion analysis of variance," Journal of the American Statistical Association, vol. 47, pp. 583-621, 1952.

[30] H. B. Mann and D. R. Whitney, "On a test of whether one of two random variables is stochastically larger than the other," The Annals of Mathematical Statistics, vol. 18, pp. 50-60, 1947.

[31] A. M. Brownawell, E. L. Carmines, and F. Montesano, "Safety assessment of AGPC as a food ingredient," Food and Chemical Toxicology, vol. 49, no. 6, pp. 1303-1315, 2011.

[32] C. A. R. A. Costa, L. T. Bidinotto, R. K. Takahira, D. M. F. Salvadori, L. F. Barbisan, and M. Costa, "Cholesterol reduction and lack of genotoxic or toxic effects in mice after repeated 21day oral intake of lemongrass (Cymbopogon citratus) essential oil," Food and Chemical Toxicology, vol. 49, no. 9, pp. 2268-2272, 2011.

[33] A. Gutiérrez, R. Gámez, M. Noa et al., "One year oral Toxicity of D-004, a lipid extract from Roystonea regia fruits, in Sprague Dawley rats," Food and Chemical Toxicology, vol. 49, no. 11, pp. 2855-2861, 2011.

[34] G. N. Lee and O. H. Kwon, Clinical Pathology File, Medical Cultural Press, Seoul, Republic of Korea, 2003.

[35] T. Yoshifumi, "Collection of questions and answers in toxicology," Scientist, Inc., 2003.

[36] Z. Z. Han, H. D. Xu, K. H. Kim et al., "Reference data of the main physiological parameters in control Sprague-Dawley rats from pre-clinical toxicity studie," Laboratory Animal Research, vol. 26, pp. 153-164, 2010.

[37] S.-H. Shin, K.-H. Koo, J.-S. Bae et al., "Single and 90-day repeated oral dose toxicity studies of fermented Rhus verniciflua stem bark extract in Sprague-Dawley rats," Food and Chemical Toxicology, vol. 55, pp. 617-626, 2013.

[38] B. H. Kang, H. Y. Son, C. S. Ha, H. S. Lee, and S. W. Song, "Reference values of hematology and serum chemistry in Ktc: Sprague-Dawley rats," Korean Journal of Laboratory Animal Science, vol. 11, pp. 141-145, 1995.

[39] S. T. Wolford, R. A. Schroer, F. X. Gohs et al., "Reference range data base for serum chemistry and hematology values in laboratory animals," Journal of Toxicology and Environmental Health, vol. 18, no. 2, pp. 161-188, 1986. 
[40] W. F. Loeb and F. W. Quimby, The Clinical Chemistry of Labolatory Animals, Pergamon Press, 1989.

[41] B. M. Schmidt, N. Ilic, A. Poulev, and I. Raskin, “Toxicological evaluation of a chicory root extract," Food and Chemical Toxicology, vol. 45, no. 7, pp. 1131-1139, 2007.

[42] D. Wang, J. Meng, K. Xu et al., "Evaluation of oral subchronic toxicity of Pu-erh green tea (camellia sinensis var. assamica) extract in Sprague Dawley rats," Journal of Ethnopharmacology, vol. 142, no. 3, pp. 836-844, 2012.

[43] M. Wang, J. Liu, B. Zhou et al., "Acute and sub-chronic toxicity studies of Danshen injection in Sprague-Dawley rats," Journal of Ethnopharmacology, vol. 141, no. 1, pp. 96-103, 2012.

[44] M.-Y. Lee, I.-S. Shin, C.-S. Seo, J.-H. Kim, S.-R. Han, and H.-K. Shin, "Subchronic oral toxicity studies of the traditional herbal formula Bangpungtongseong-san in Crl: CD (SD) rats," Journal of Ethnopharmacology, vol. 144, no. 3, pp. 720-725, 2012.

[45] Y.-H. Lee, D. Kim, M. J. Lee et al., "Subchronic toxicity study of Coptidis Rhizoma in rats," Journal of Ethnopharmacology, vol. 152, no. 3, pp. 457-463, 2014.

[46] G. A. Boorman, S. L. Eustis, M. R. Elwell et al., Pathology of the Fischer Rat, New York, NY, USA, Academic Press, 1990.

[47] P. Greves, Histopathology of Preclinical Toxicity Studies, Interpretation and Relevance in Drug Safety Evaluation, Elsevier, 2000.

[48] M. Y. Ahn, S. C. Kang, N. J. Jung et al., "Acute oral toxicity of Paecilomyces sinclairii in beagle dogs," Journal of Toxicology and Public Health, vol. 19, no. 3, pp. 241-245, 2003.

[49] S. H. Kim, S. J. Park, and Y. S. Yun, "Acute oral toxicity test of oriental medical preseription SH21-B," Journal of Oriental Medicine, vol. 9, pp. 131-148, 2003.

[50] R. A. Isbrucker, J. A. Edwards, E. Wolz, A. Davidovich, and J. Bausch, "Safety studies on epigallocatechin gallate (EGCG) preparations. Part 2. Dermal, acute and short-term toxicity studies," Food and Chemical Toxicology, vol. 44, no. 5, pp. 636650, 2006.

[51] N. Sun, G. Lu, M. Lin, G. Fan, and Y. Wu, "Subchronic toxicity and toxicokinetics of MCC-555, a novel thiazolidinedione, after 270-day repeated oral administration in dogs," Environmental Toxicology and Pharmacology, vol. 27, no. 2, pp. 237-246, 2009.

[52] H.-S. Chung, H. J. Lee, I. Shim, and H. Bae, "Assessment of antidepressant effect of nelumbinis semen on rats under chronic mild stress and its subchronic oral toxicity in rats and beagle dogs," BMC Complementary and Alternative Medicine, vol. 12, article 68, 2012.

[53] G. A. Burdock and W. G. Flamm, "A review of the studies of the safety of polydextrose in food," Food and Chemical Toxicology, vol. 37, no. 2-3, pp. 233-264, 1999.

[54] R. M. McClain, E. Wolz, A. Davidovich, F. Pfannkuch, and J. Bausch, "Subchronic and chronic safety studies with genistein in dogs," Food and Chemical Toxicology, vol. 43, no. 10, pp. 14611482, 2005.

[55] C. Elwood, P. Devauchelle, J. Elliott et al., "Emesis in dogs: a review," Journal of Small Animal Practice, vol. 51, no. 1, pp. 4-22, 2010.

[56] I. M. Lang, S. K. Sarna, and R. E. Condon, "Gastrointestinal motor correlates of vomiting in the dog: quantification and characterization as an independent phenomenon," Gastroenterology, vol. 90, no. 1, pp. 40-47, 1986.

[57] J. Xu and J. D. Z. Chen, "Intestinal electrical stimulation improves delayed gastric emptying and vomiting induced by duodenal distension in dogs," Neurogastroenterology \& Motility, vol. 20, no. 3, pp. 236-242, 2008.
[58] C. L. Chernicky, K. L. Barnes, J. P. Conomy, and C. M. Ferrario, "A morphological characterization of the canine area postrema," Neuroscience Letters, vol. 20, no. 1, pp. 37-43, 1980.

[59] M. Tobe, T. Furuya, Y. Kawasaki et al., "Six-month toxicity study of butylated hydroxyanisole in beagle dogs," Food and Chemical Toxicology, vol. 24, no. 10-11, pp. 1223-1228, 1986.

[60] H. P. Til and A. Bär, "Subchronic (13-week) oral toxicity study of $\gamma$-cyclodextrin in dogs," Regulatory Toxicology and Pharmacology, vol. 27, no. 2, pp. 159-165, 1998.

[61] C. D. Hébert, H. D. Giles, J. E. Heath, D. B. Hogan, J. P. Modderman, and R. E. Conn, "Toxicity of lactide in dogs after 2 and 13 weeks of daily oral dosing," Food and Chemical Toxicology, vol. 37, no. 4, pp. 335-342, 1999.

[62] Y. Mao, X. Zhang, L. Li, B. Yuan, and G. Lu, "Subchronic toxicity and toxicokinetics of LZB, a new proton pump inhibitor, after 13-week repeated oral administration in dogs," Regulatory Toxicology and Pharmacology, vol. 50, no. 1, pp. 75-86, 2008.

[63] H. Koop, "Review article: metabolic consequences of longterm inhibition of acid secretion by omeprazole," Alimentary Pharmacology and Therapeutics, vol. 6, no. 4, pp. 399-406, 1992.

[64] K. Yamashita, S. Nakano, M. Kuwata et al., "Single dose toxicity studies of suplatast tosilate (IPD-1151T)," The Journal of Toxicological Sciences, vol. 17, no. 2, pp. 1-9, 1992.

[65] Cargill, Acute Oral Toxicity Study of Lacide 2097-99-2 in Rats (EPA Guidelines), 1993.

[66] I. M. Kapetanovic, J. A. Crowell, R. Krishnaraj, A. Zakharov, M. Lindeblad, and A. Lyubimov, "Exposure and toxicity of green tea polyphenols in fasted and non-fasted dogs," Toxicology, vol. 260, no. 1-3, pp. 28-36, 2009.

[67] M. S. Werley, P. McDonald, P. Lilly et al., "Non-clinical safety and pharmacokinetic evaluations of propylene glycol aerosol in Sprague-Dawley rats and Beagle dogs," Toxicology, vol. 287, no. 1-3, pp. 76-90, 2011.

[68] M. Kaszkin-Bettag, A. Richardson, R. Rettenberger, and P. W. Heger, "Long-term toxicity studies in dogs support the safety of the special extract ERr 731 from the roots of Rheum rhaponticum," Food and Chemical Toxicology, vol. 46, no. 5, pp. 1608-1618, 2008. 


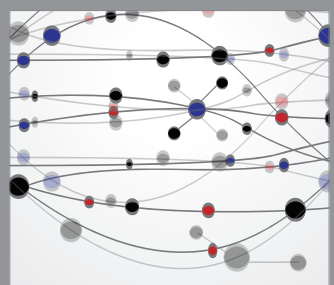

The Scientific World Journal
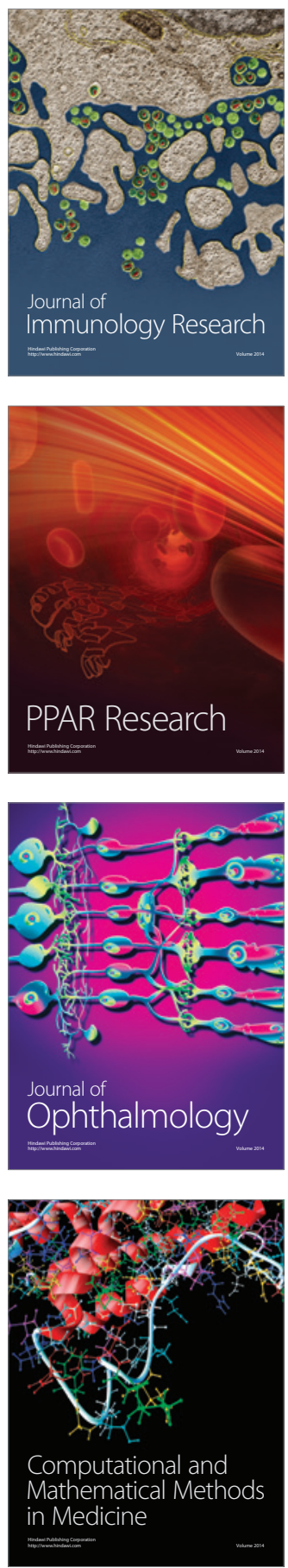

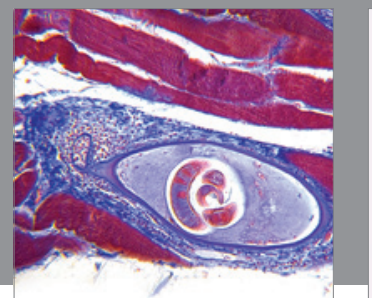

Gastroenterology

Research and Practice
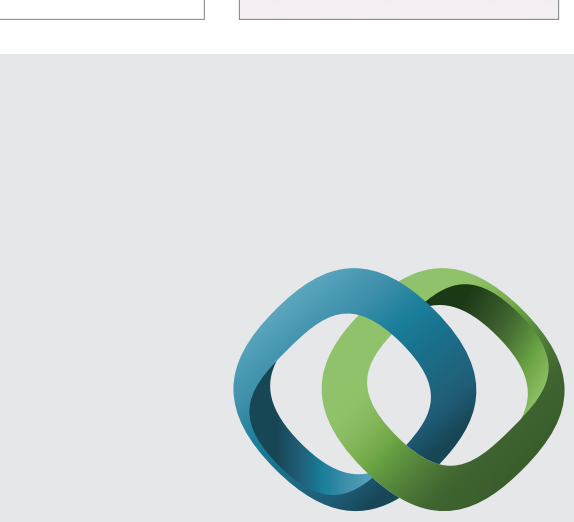

\section{Hindawi}

Submit your manuscripts at

http://www.hindawi.com
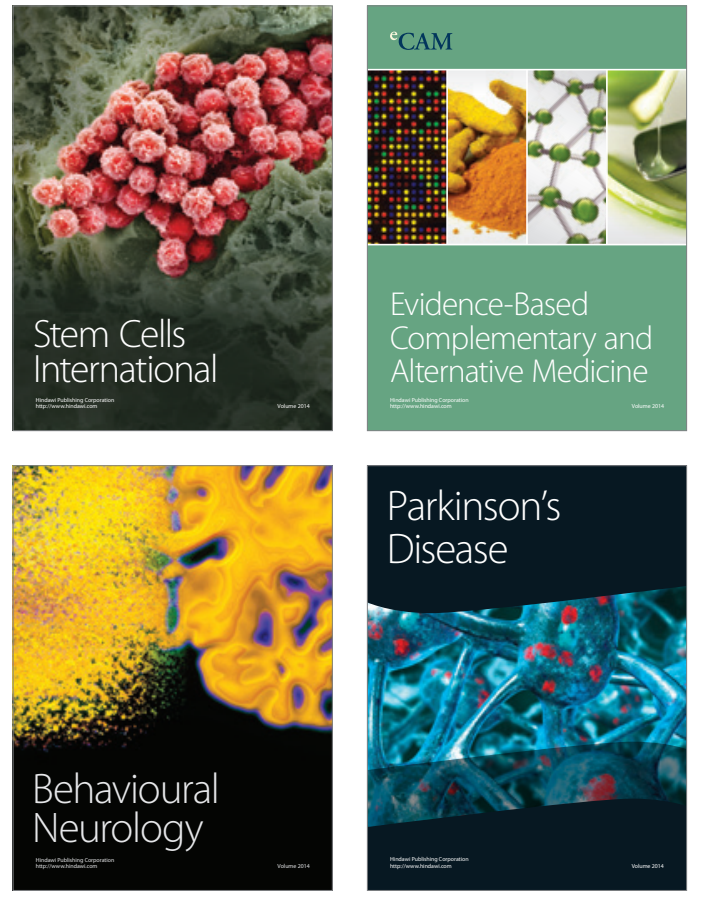
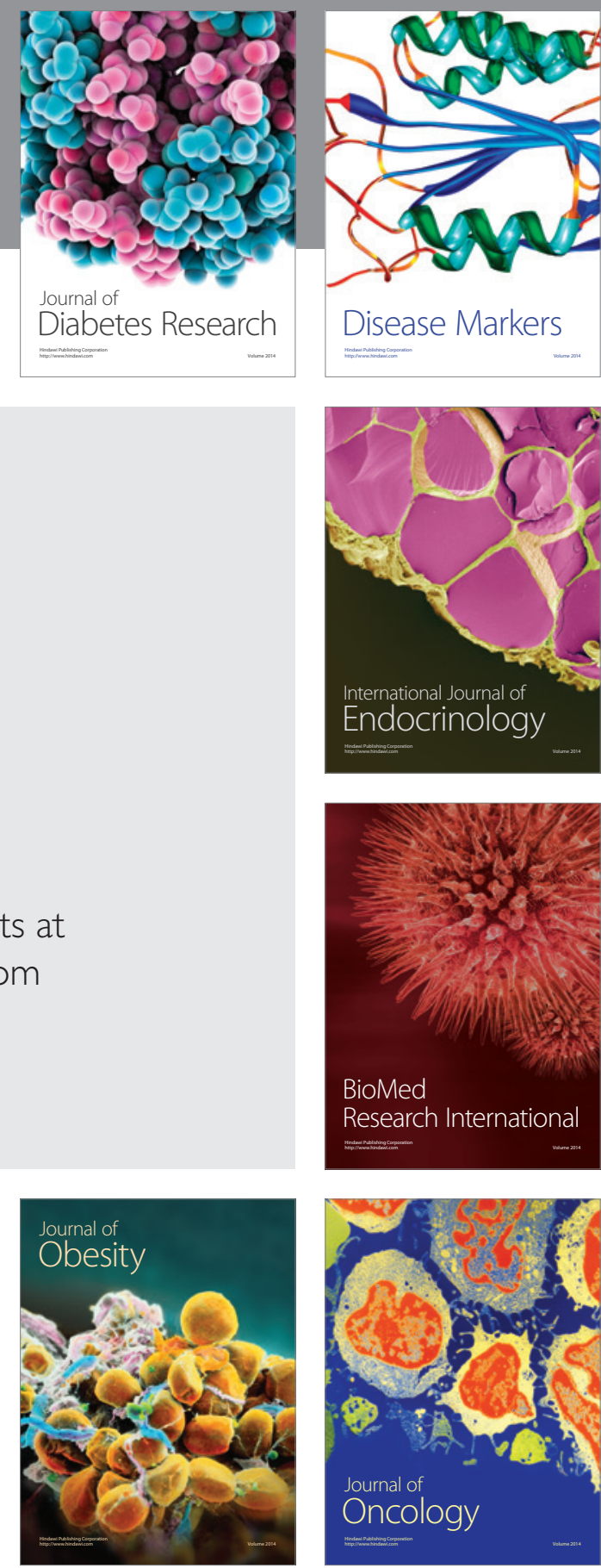

Disease Markers
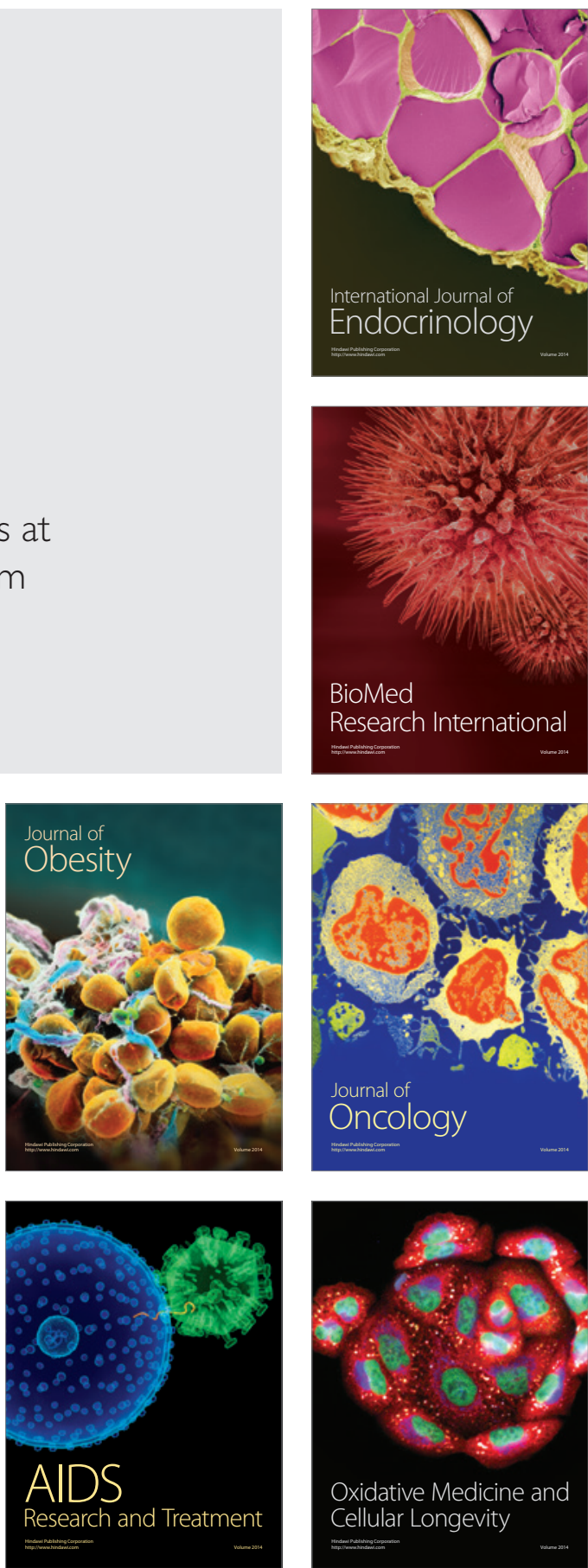